\title{
Earthquake Failure Sequences Along a Cellular Fault Zone in a Three-Dimensional Elastic Solid Containing Asperity and Nonasperity Regions
}

\author{
YEHUDA BEN-ZION AND JAMES R. RICE \\ Department of Earth and Planetary Sciences and Division of Applied Sciences, Harvard University, Cambridge, Massachusetts
}

\begin{abstract}
Numerical simulations of earthquake failure sequences along a discrete cellular fault zone are performed for a three-dimensional (3-D) model representing approximately the central San Andreas fault. The model consists of an upper crust overlying a lower crust and mantle region, together defining an elastic half-space with a vertical half-plane fault. The fault contains a region where slip is calculated on a uniform grid of cells governed by a static/kinetic friction law and regions where slip is prescribed so as to represent tectonic loading, aseismic fault creep, and adjacent great earthquakes. The computational region models a 70-km-long and $17.5-\mathrm{km}$-deep section of the San Andreas fault to the NW of the great 1857 rupture zone. Different distributions of stress drops on failing computational cells are used to model asperity ("Parkfield asperity") and nonasperity fault regions. The model is "inherently discrete" and corresponds to a situation in which a characteristic size of geometric disorder within the fault (i.e., cell size, here a few hundreds of meters) is much larger than the "nucleation size" (of the order of tens of centimeters to tens of meters) based on slip weakening or state evolution slip distances. The computational grid is loaded by a constant plate motion imposed at the lower crust, upper mantle, and creeping fault regions and by a "staircase" slip history imposed at the 1857 and 1906 rupture zones. Stress transfer along and outside the fault due to the imposed loadings and failure episodes along the computational grid is calculated using 3-D elastic dislocation theory. The resulting displacement field in the computational region is compatible with geodetic and seismological observations only when the asperity and nonasperity regions are characterized by significantly different average stress drops. The frequency-magnitude statistics of the simulated failure episodes are approximately self-similar for small events, with $b \approx 1.2$ (the $b$ value of statistics based on rupture area $b_{\mathrm{A}}$ is about 1 ) but are strongly enhanced with respect to self-similarity for events larger than a critical size. This is interpreted as a direct manifestation of our 3-D elastic stress transfer calculations; beyond certain rupture area and potency (seismic moment divided by rigidity) release values, the event is usually unstoppable, and it continues to grow to a size limited by a characteristic model dimension. This effect is not accounted for by cellular automata and block-spring models in which the adopted simplified stress transfer laws fail to scale properly with increasing rupture size. The simulations suggest that local maxima in observed frequency-magnitude statistics correspond to dimensions of coherent brittle zones, such as the width of the seismogenic layer or the length of a fault segment bounded by barriers. The analysis indicates that a single cell size, representing approximately a single scale of geometric disorder, cannot induce self-similarity in a 3-D elastic model over a broad range of magnitudes. A representation of geometric disorder covering a range of scales may thus be required to generate a wide domain of self-similar Gutenberg-Richter statistics. Our simulations show a great diversity in the mode of failure of the Parkfield asperity; the earthquakes themselves define an irregular sequence of events. The modeling, like many other discrete fault models, suggests that expectations for periodic Parkfield earthquakes and/or simple precursory patterns repeating from one event to the other are unrealistic.
\end{abstract}

\section{INTRODUCTION}

In the last decade there has been mounting evidence that the crust in general and fault zones in particular are heterogeneous on many scale lengths. Interevent distance statistics of global earthquakes [Kagan, 1991], profilometry

Copyright 1993 by the American Geophysical Union.

Paper number 93JB01096. 0148-0227/93/93JB-01096\$05.00 measurements along exhumed fault surfaces [Power et al., 1988; Power and Tullis, 1991], characterization of mapped San Andreas fault (SAF) traces [Aviles et al., 1987; Okubo and $A k i, 1987]$, and analysis of sonic velocity and electrical resistivity logs from the deep Cajon Pass scientific borehole [Leary, 1991] indicate that fractures in crustal rocks are characterized by fractal-like distribution in space. The well-known Gutenberg-Richter (GR) statistics, relating the frequency of earthquake occurrence with earthquake magnitude, emphasize the spatial and temporal non- 
uniformity of fault slip and indicate that, within limits, earthquake statistics are scale invariant or fractal. On the other hand, plate tectonics and rheology bring about distinct large-scale mechanical regimes such as locked and creeping fault segments [e.g., Allen, 1968] and brittle and stably sliding depth sections [e.g., Sibson, 1982; Tse and Rice, 1986] within which the complex smaller-scale fractures develop.

The purpose of this work is to develop a model for fault instabilities (earthquakes) incorporating both the large-scale mechanical regimes and the small-scale complex fracture heterogeneities. The model consists of an upper crust overlying a lower crust and upper mantle region, together defining an elastic half-space with a vertical half-plane fault. In present applications the model corresponds to the central SAF. The fault contains a computational region where slip is calculated on a grid of cells governed by a static/kinetic friction law and regions where imposed slip represents tectonic loading, aseismic fault creep, and adjacent great earthquakes. Stress transfer along and outside the fault is calculated using the three-dimensional (3-D) solution of Chinnery [1963] for static dislocations on rectangular patches in an elastic half-space.

The evolution of stress and displacement fields is calculated in our model in a quasi-static fashion. The dynamics of quasi-static systems is governed by the constitutive law giving the relation between stress and slip on failing elements and by the stress transfer function describing the spatial redistribution of stress due to slip episodes. Rice [1993] classified models of fault instabilities based on the used constitutive law. When the constitutive stress-slip relation includes a finite slip distance over which the strength of failing elements evolves continuously, i.e., a slip weakening or state transition slip distance $L$, the model has a well-defined continuum limit which can be approached for small enough numerical cells. When, however, the strength of failing elements drops discontinuously with slip, as in the present work, or is dependent only on the velocity of slip such that no finite distance $L$ is included in the constitutive law, the model is inherently discrete. In models with a continuum limit, suitably refined cells can fail only as members of a cooperating group, whereas in inherently discrete models, cells can fail individually regardless of how small they are. When a continuum limit exists, the cell size $h$ of a suitably refined grid must be small compared to a "nucleation size" $h^{*}$. The size $h^{*}$ scales with $L$ but is orders of magnitude larger ( $2 \times 10^{4}$ to $10^{5}$ in cases addressed by Rice [1993]) since it is given as $L$ multiplied by the shear rigidity $\mu$ divided by a measure of weakening, e.g., by $-V d \tau_{\mathrm{ss}}(V) / d V$ in rate- and state-dependent friction, where $\tau_{\mathrm{ss}}(V)$ is the steady state shear resistance at slip rate $V$. For $L$ between 5 and $500 \mu \mathrm{m}, h^{*}$ is estimated to lie in the range of tens of centimeters to tens of meters.
Evidently, models with a continuum limit form a different class of dynamical systems than do inherently discrete models. Rice [1993] found in his simulations of slip on a smooth vertical fault surface with cell size $h \ll$ $h^{*}$ that the generic model response is a simple limit cycle of repeated earthquakes. (Spatiotemporally complex slip can be found in similar simulations for special parameter choices [Horowitz and Ruina, 1989] or with strong variation of velocity weakening properties along strike [Rice, 1992].) In contrast, the generic response of inherently discrete systems (generated by Rice [1993] by choosing a cell size $h \gg h^{*}$ ) gives a spectrum of event sizes, generally with some range of self-similar scaling and GR statistics. Such behavior is found in the present work and has been reported in analyses of far simpler models of the inherently discrete class, in which the dimension of the system is the same as that of the fault, rather than one greater as for a one-dimensional (1-D) or two-dimensional (2-D) fault embedded in, respectively, a 2-D or 3-D surrounding medium. Those works involve cellular automata [Bak and Tang, 1989; Ito and Matsuzaki, 1990; J. Lomnitz-Adler, manuscript in preparation, 1993] or Burridge and Knopoff [1967] arrays of spring-connected rigid blocks [Carlson and Langer, 1989; Carlson, 1991; Carlson et al., 1991; Brown et al., 1991; Christensen and Olami, 1992]. The cellular automata and block-spring models with system dimension equal to fault dimension, while inherently discrete like the present work, greatly simplify the stress transfer function to nearest neighbor interactions that do not scale with rupture size in a way suitable to represent a fault embedded in a 3-D elastic continuum.

Since the constitutive laws of inherently discrete systems do not contain a critical slip distance, these models are not able to address questions related to crack tip phenomena in faulting and to the nucleation of fault instabilities in the sense of Dieterich [1986] and Tse and Rice [1986]. On the other hand, detailed modeling of observed seismic data in terms of earthquake rupture propagation always requires the use of discrete fault elements such as barriers, asperities, and short-rise-time dislocations [e.g., Aki, 1984; Gusev, 1989; Heaton, 1990]. In addition, the generic response of the class of models with a continuum limit does not account for the spatio-temporal complexity of observed fault slip and the related observed frequency-magnitude (FM) statistics of earthquakes [e.g., Rice, 1993]. It thus appears that realistic modeling of the growth of fault instabilities (i.e., the interaction between different sections along the fault) should include some use of discrete fault patches. These are presumably related to geometrical, material, pore pressure, and/or stress heterogeneities along the fault. As noted above, the studies of Aviles et al. [1987], Okubo and Aki [1987], Power et al. [1988], and others indicate that fault zones are characterized 


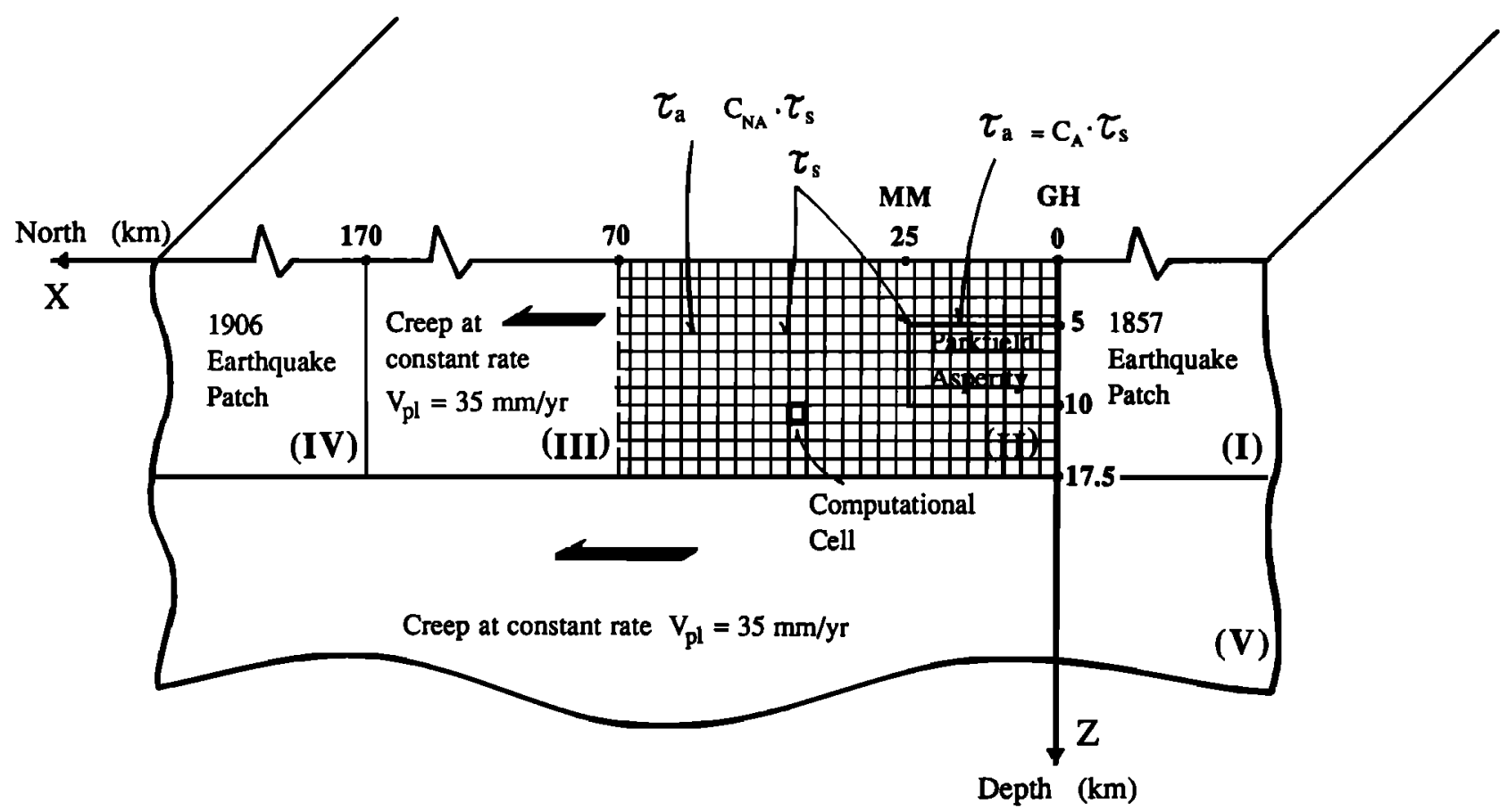

Fig. 1a. A model for the central San Andreas fault (SAF), $\tau_{\mathrm{S}}$ is static strength assumed homogeneous over the computational region, $\tau_{\mathrm{a}}$ is arrest stress, $C_{\mathrm{A}}$ and $C_{\mathrm{NA}} \geq C_{\mathrm{A}}$ are numerical coefficients, and $\mathrm{GH}$ and $\mathrm{MM}$ mark approximate positions of Gold Hill and Middle Mountain. See text for more explanation.

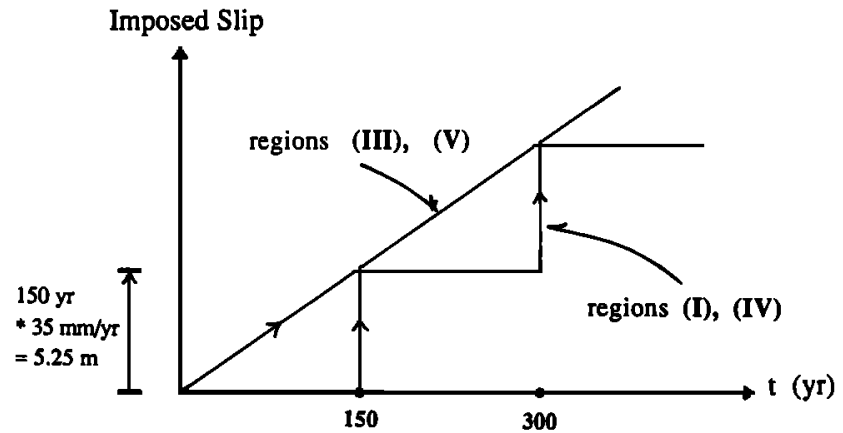

Fig. 1b. Imposed slip modeling tectonic loading, aseismic fault creep, and large 1857 and 1906 type earthquakes.

by geometric disorder that covers a wide range of size scales. In the presence of fault bends, forks, and step-overs, and/or complex fault wall topography, a fault segment may fail independently of an adjoining region in a way prohibited by the large stress concentration at the front of a slip event spreading along a smooth surface. Thus we interpret the cells of our inherently discrete fault model as representing quasi-independent fault segments of size (equal to cell size $h$ ) that is large compared to $h^{*}$. An open question, to which we return in the discussion, is whether a single size scale of geometric disorder, represented approximately by a grid of uniform size cells, can induce self-similar GR statistics over a broad magnitude range in a realistic 3-D model.

Additional observations that might be related to some form of discreteness in the earthquake rupture process are the constancy of radiated seismic corner frequency for earthquakes in the low-magnitude range [e.g., Bakun et al., 1976; Chouet et al., 1978; Fletcher, 1980], the related observation of strong variation of earthquake stress drop for small events [e.g., Sacks and Rydelek, 1992; Hough et al., 1992], and the occurrence of repeated earthquakes such as those observed in large numbers at Parkfield, California, [Antolik et al., 1991] and Volcano Usu in Japan [Okada et al., 1981]. Observations showing flattening of FM curves in the low-magnitude range [e.g., Aki, 1987; Malin et al., 1989; Rydelek and Sacks, 1989; Sacks and Rydelek, 1992] can also be interpreted as resulting from fault zone discreteness, although other explanations (e.g., a transition from brittle failure to creep) exist. We note that the interpretation of the constancy of seismic corner frequency, the strong variation of stress drops, and the flattening of FM curves, for earthquakes in the low-magnitude range, is controversial. Some seismologists [e.g., Anderson, 1986; Hanks, 1992] attribute these observations to sampling and recording site effects, while others [e.g., Aki, 1987; Rydelek and Sacks, 1989] attribute them to the earthquake source. In particular, Rydelek and Sacks [1989] and Malin et al. [1989] claim that their earthquake catalogs are complete in the relevant low-magnitude range, and Hough et al. [1992] used the, presumably accurate, empirical Green's function approach to estimate the (constant) rupture area of their small events. Abercrombie and Leary [1993] recently observed in the Cajon Pass borehole, at a depth of $2.5 \mathrm{~km}$, corner frequencies of natural earthquakes that correspond to slip patches as small as $10 \mathrm{~m}$. The data of 
Abercrombie and Leary argue convincingly against the existence of a minimum earthquake dimension of the order of a few hundreds of meters. It is possible, however, that observations such as those of Antolik et al. [1991], Sacks and Rydelek [1992] and Hough et al. [1992] are related to "effective" discreteness in fault zones due to, e.g., geometrical disorder as discussed above. A scale length of the order of $100 \mathrm{~m}$ that might affect the source volume, and hence the size of slip patches, of small earthquakes is the width of fault zones, as indicated from modeling of fault zone seismic trapped and head waves [Leary and Ben-Zion, 1992; Ben-Zion, 1993; S. E. Hough et al., manuscript in preparation, 1993]. The studies of Malin et al. [1989], Antolik et al. [1991], Sacks and Rydelek [1992], Leary and Ben-Zion [1992], Hough et al. [1992; manuscript in preparation, 1993], and Ben-Zion [1993] suggest that the dimension of small, effectively disconnected, slip patches in mature fault zones may be of the order of a few hundreds of meters.

An important unresolved question is whether the spatiotemporal complexity of fault slip can be attributed purely to fault dynamics or whether nonuniformities in geometry, material properties, or mode of loading are essential for understanding the observed complex fault slip. The cellular automata and block-spring studies mentioned above simulated successfully aspects of the observed complex fault slip using discrete uniform systems governed by strongly nonlinear dynamics. In the present work we attempt to clarify the dynamics of inherently discrete models when stress interactions are controlled by 3-D elasticity. This is done in the context of a particular fault zone, that of the central SAF, so that model simulations could be compared with specific (as opposed to averaged or generic) data. Although the origin of fault slip complexities cannot be fully understood until the inertia-controlled elastodynamics of rupture propagation is included in the modeling, the quasi-static simulations for a fault embedded in a 3-D surrounding continuum, done here and by Rice [1992, 1993], suggest that strong heterogeneities capable of stopping ruptures of various sizes are probably responsible for the observed complex fault slip.

The cases examined in our work cover varying degrees of model heterogeneity. In the least heterogeneous case, the computational grid has uniform properties and model heterogeneity comes only from the inherently discrete cellular fault structure and the assumed loadings. In more heterogeneous cases, the computational grid contains property variations. Our results show spatio-temporal slip complexities for all cases; however, the calculated displacement field is compatible with geodetic and seismological data from the Parkfield region only when strong property variation is assumed along the fault. The frequency-size (FS) statistics of the simulated failure episodes are self-similar for small events with $b \approx 1.2$ and $b_{\mathrm{A}} \approx 1$, where $b$ and $b_{\mathrm{A}}$ are $b$ values based on magnitude and rupture area, respectively (here and later FS is used as a general reference to statistics based on either earthquake magnitude or rupture area, FM refers to statistics based on earthquake magnitude, and GR refers to power law, i.e., $\log$-log linear, FS statistics). For events larger than a threshold size, however, the simulated FS statistics are strongly enhanced with respect to self-similarity. This is a direct manifestation of the 3-D elastic stress transfer calculations used in our model; beyond critical rupture area (apparently scaling directly with cell area $h^{2}$ ) and potency release values, the event is usually unstoppable, and it continues to grow to a size limited by a characteristic model dimension. This effect is not accounted for by cellular automata and block-spring simulations where the employed simplified stress transfer laws do not scale properly with increasing rupture size. The supercritical rupture growth in our simulations results in FS statistics
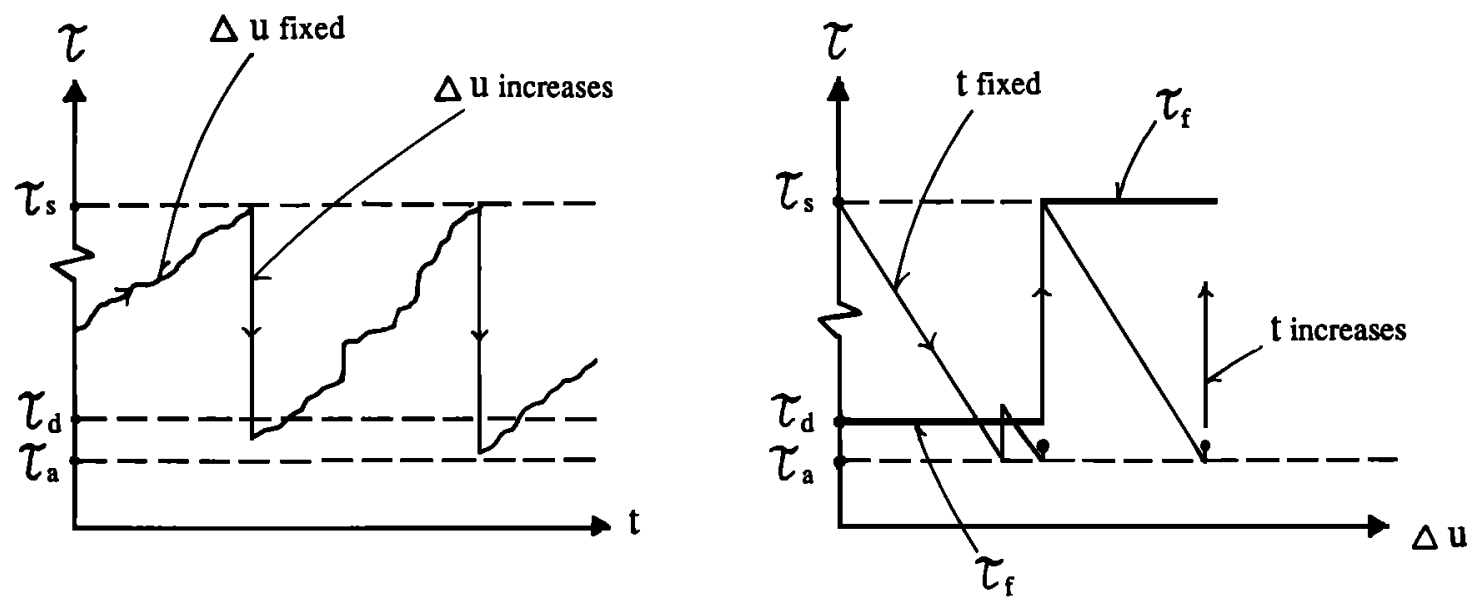

Fig. 2. Schematic diagrams of stress-time and stress-slip relations at the center of computational cells. Static strength, dynamic strength, arrest stress, and failure stress are denoted, respectively, by $\tau_{\mathrm{s}}, \tau_{\mathrm{d}}, \tau_{\mathrm{a}}$, and $\tau_{\mathrm{f}}$. 
showing local maxima for events having rupture areas corresponding to the upper layer thickness and the entire computational grid. Similar local maxima in the rate of occurrence of events having specific rupture dimensions are present in observed frequency-magnitude statistics of local earthquake catalogs [Schwartz and Coppersmith, 1984; S. G. Wesnousky, The Gutenberg-Richter or characteristic earthquake distribution, which is it?, submitted to Bulletin of the Seismological Society of America, 1993; hereinafter referred to as Wesnousky, submitted manuscript, 1993] (but see Kagan [1993]) and in regional FM data from approximately uniform seismogenic zones [Main and Burton, 1984; Main, 1987; Main and Burton, 1989; Trifu and Radulian, 1991].

A related important issue to fault slip complexities is the affinity of fault heterogeneity to "characteristic" earthquakes and precursory patterns around presently locked asperities. Rice [1993] found that fault segments that differ in their rate- and state-dependent friction parameters by about $10 \%$ adopt a coordinated response with a common recurrence interval (phase locking), rather than quasiindependent responses consistent with their individual properties. Similarly, our model requires a significant property variation in order to generate a Parkfield-type asperity. Our simulated results show an irregular sequence of Parkfield-type earthquakes and a great diversity in the failure mechanism of the model asperity; some failure events are preceded by a period of accelerated potency release and/or foreshocks, some events resemble slow earthquakes, and other events are abrupt. We thus suggest that scenarios of earthquake prediction based on simple repetitive cycles are unrealistic. It is possible, however, that some precursors exist, for example, in the form of evolving microseismicity patterns. A feedback between precise monitoring of microearthquakes [e.g., Antolik et al., 1991] and theoretical simulations of earthquake failure sequences may facilitate the identification of such patterns, if they exist.

\section{ANALYSIS}

Our model (Figure 1a) consists of a layered elastic halfspace with a vertical half-plane fault. The half-space has a 17.5-km-thick upper crust over a lower crust and upper mantle region where stable sliding occurs. The model is tailored to the SAF in central California, where extensive seismic, geodetic, and other geophysical instruments monitor the fault in anticipation of the recurrent $M 6$ Parkfield earthquakes [Bakun and McEvilly, 1984; Bakun and Lindh, 1985]. The fault region in the upper crust contains large earthquake patches (regions I and IV) representing the rupture zones of the 1857 and 1906 M8 events. On these patches we impose a staircase slip history with a recurrence time of 150 years. Everywhere along the lower crust and upper mantle (region V) and in the upper

\section{Dislocation algorithm}

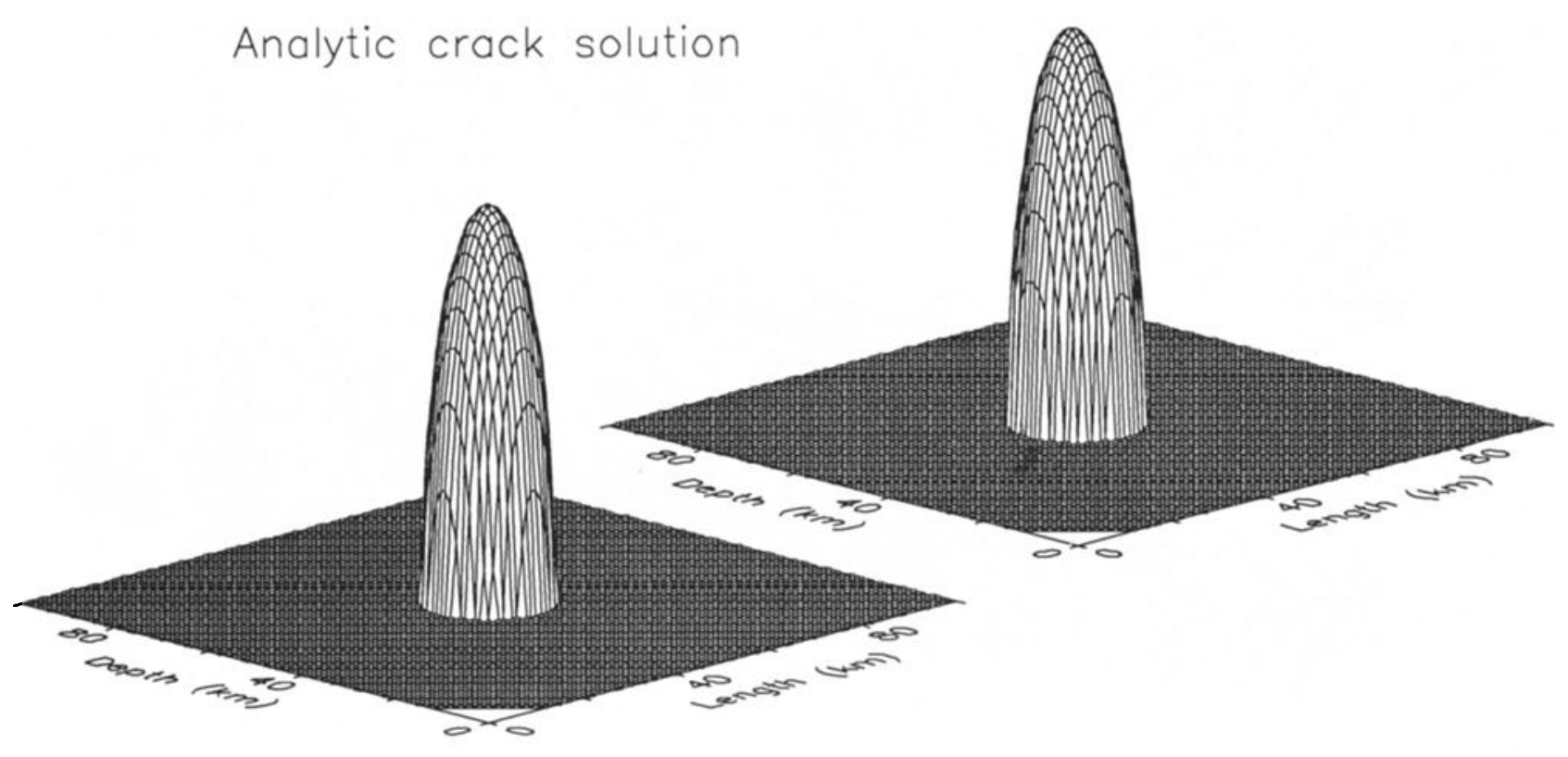

Fig. 3. Slip on a circular crack in a full space calculated using an analytical solution (left) and the dislocation-based algorithm of this paper (right). Calculated slip values at the edge and center of the crack differ by $1 / 8$ and $1 / 250$, respectively. 
crust fault segment that is distant from Gold Hill (GH) by more than $70 \mathrm{~km}$ (region III) we impose slip at a constant plate rate $V_{\mathrm{pl}}=35 \mathrm{~mm} / \mathrm{yr}$ (Figure $1 b$ ). Time-dependent effects due to viscoelasticity in the lower crust and upper mantle [e.g., Li and Rice, 1987; Ben-Zion et al., 1993] are ignored at the present level of modeling. The upper crust fault segment $0 \leq x \leq 70 \mathrm{~km}, 0 \leq z \leq 17.5 \mathrm{~km}$ comprises a computational grid where space and time evolution of stress and displacement fields due to the imposed slip (Figure $1 b$ ) are calculated using a variant of static/dynamic friction law and 3-D continuum elasticity. The computational grid contains "asperity" and "nonasperity" regions. The asperity (referred to as the "Parkfield Asperity") extends from GH to Middle Mountain (MM) between the depths of 5 and $10 \mathrm{~km}$, in agreement with geodetic data [e.g., Harris and Segall, 1987] and the microearthquake distribution of Malin et al. [1989]. We assume that everywhere along the computational grid the static strength $\tau_{\mathrm{s}}$ is uniform. This is motivated by the fact that laboratory measurements of peak sliding resistance are largely independent of the rock type [e.g., Byerlee, 1978]. This leaves differences in fault properties to be attributed to dynamical processes which we simply model here by assigning different levels of dynamic strength $\tau_{\mathrm{d}}$ and arrest stress $\tau_{\mathfrak{a}}$ to different fault regions.

Consider a failure process involving a fault segment represented by a single cell of the computational grid. When the stress $\tau$ on the fault segment (cell) reaches the level $\tau_{\mathrm{s}}$, failure occurs and the segment slips at $\tau=\tau_{\mathrm{d}}$ $\left(<\tau_{\mathrm{S}}\right)$ until the rupture is blocked by the segment borders. Then, slip on the cell is brought to a halt, leaving on the failed segment an arrest stress $\tau_{a}\left(<\tau_{d}\right)$. If the stress transferred from the failed segment increases the stress at other fault regions to their failure thresholds those regions fail, causing additional stress transfers which, in turn, may induce or reinduce more slip events. We assume that reinitiation of slip on an already failed cell occurs when $\tau \geq$ $\tau_{d}$ there. Thus $\tau_{s}$ is the failure strength of a segment which has not yet slipped in a composite event, $\tau_{d}$ is the failure strength of a segment which has slipped in an earlier subevent, and $\tau_{\mathrm{a}}$ is the stress remaining on a cell just after it has slipped and before stress transfers from other segments failing at the same time have occurred. The conceptual picture of rupture adopted in this study is thus that of a composite failure process, made of subevents that are dominated by geometric heterogeneities. The latter

\section{Slip along the SAF}

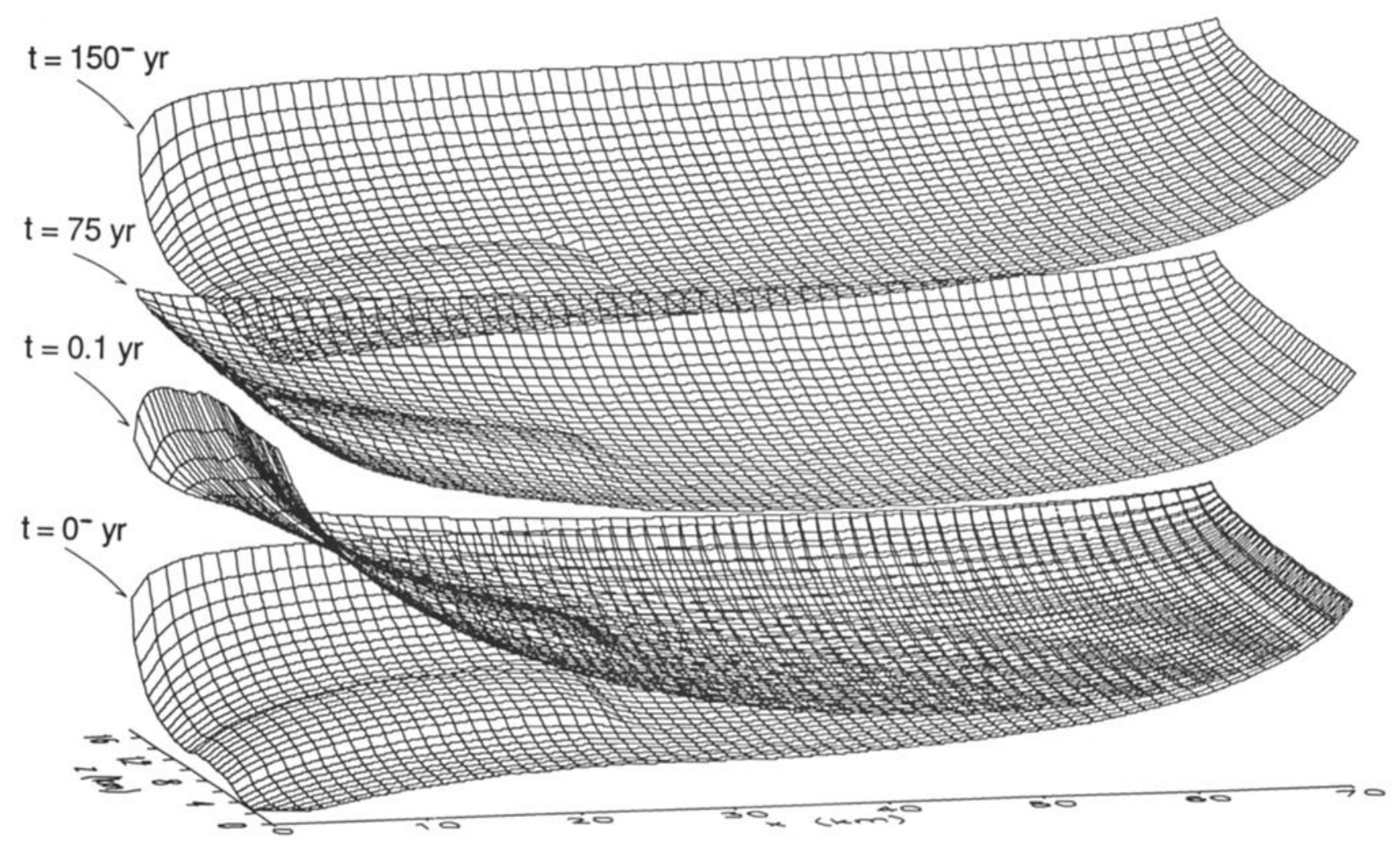

Fig. 4. Slip distributions along the SAF at various times throughout the imposed 150 year great earthquake cycle. The static strength is $\tau_{\mathrm{s}}=40$ bars. In the asperity region the arrest stress is $\tau_{\mathrm{a}}=0.1 \tau_{\mathrm{s}}$; in the nonasperity region $\tau_{\mathfrak{a}}=0.9 \tau_{\mathrm{s}}$. Note that the asperity is reflected on the various slip surfaces. 
define segment borders, arrest elementary subevents, and require that slip be initiated or reinitiated by stress transfers for rupture to continue.

The static strength, dynamic strength, and arrest stress are related to each other as

$$
\left(\tau_{\mathrm{s}}-\tau_{\mathrm{a}}\right) /\left(\tau_{\mathrm{s}}-\tau_{\mathrm{d}}\right)=D
$$

where $D$ is a dynamical overshoot coefficient. Numerical simulations of Madariaga [1976] indicate that $D$ for a rupture propagating in a 3-D elastic solid is about 1.25. The difference $\tau(i, j)-\tau_{\mathrm{a}}(i, j)$ gives a transient stress drop on cell $(i, j)$ during a composite failure episode, where $i$ and $j$ are, respectively, cell indexes along the horizontal and vertical directions and $\tau(i, j)$ is the stress just before failure. The final stress drop on cell $(i, j)$ is usually less than $\tau(i, j)$ - $\tau_{\mathrm{a}}(i, j)$ due to subsequent failures of other cells, but it is always greater or equal to $\tau(i, j)-\tau_{\mathrm{d}}(i, j)$.

Figure 2 illustrates representative stress-time and stressslip relations and the algorithm used for modeling failures in this work. Stress on cell $(i, j)$ accumulates with time either gradually owing to the continuous tectonic loading or abruptly owing to failures at other cells. When $\tau(i, j) \geq \tau_{\mathrm{s}}$, cell $(i, j)$ fails, and it slips so as to reduce its stress to the arrest level $\tau_{\mathrm{a}}(i, j)$. In addition, the strength of cell $(i, j)$ drops to the dynamic level $\tau_{\mathrm{d}}(i, j)$ for the duration of the present failure episode. Failure and slip at cell $(i, j)$ continue if $\tau(i, j)$ is raised above $\tau_{\mathrm{d}}(i, j)$ owing to subsequent failures elsewhere along the fault (i.e., rupture propagation). At the end of the failure episode the stress on cell $(i, j)$ is distributed between the levels $\tau_{\mathrm{d}}(i, j)$ and $\tau_{\mathbf{a}}(i, j)$, with the actual value depending on the failure sequence.

For the asperity cells we assume that $\tau_{\mathrm{a}}(i, j)$ are small fractions (e.g., 0.1) of $\tau_{\mathrm{s}}$, while in the nonasperity region, $\tau_{\mathrm{a}}(i, j)$ are assumed to be close to $\tau_{\mathrm{s}}\left(\right.$ e.g., $\tau_{\mathrm{a}}(i, j) \approx 0.8 \tau_{\mathrm{s}}$ ). Thus, failing cells at the asperity and nonasperity regions experience large and small stress drops, respectively. Large stress drops on failing asperity cells tend to propagate the rupture throughout the entire asperity (or the whole model), resulting in relatively few large asperity events separated by relatively long time intervals. In contrast, small stress drops on failing nonasperity cells generate, in general, frequent small events in the nonasperity region. Our assumed distribution of stress drops is compatible with the studies of $O^{\prime} N e i l l$ [1984] and Malin et al. [1989], where microearthquakes with an order of magnitude higher stress drops than the usual low stress drop seismicity are found to

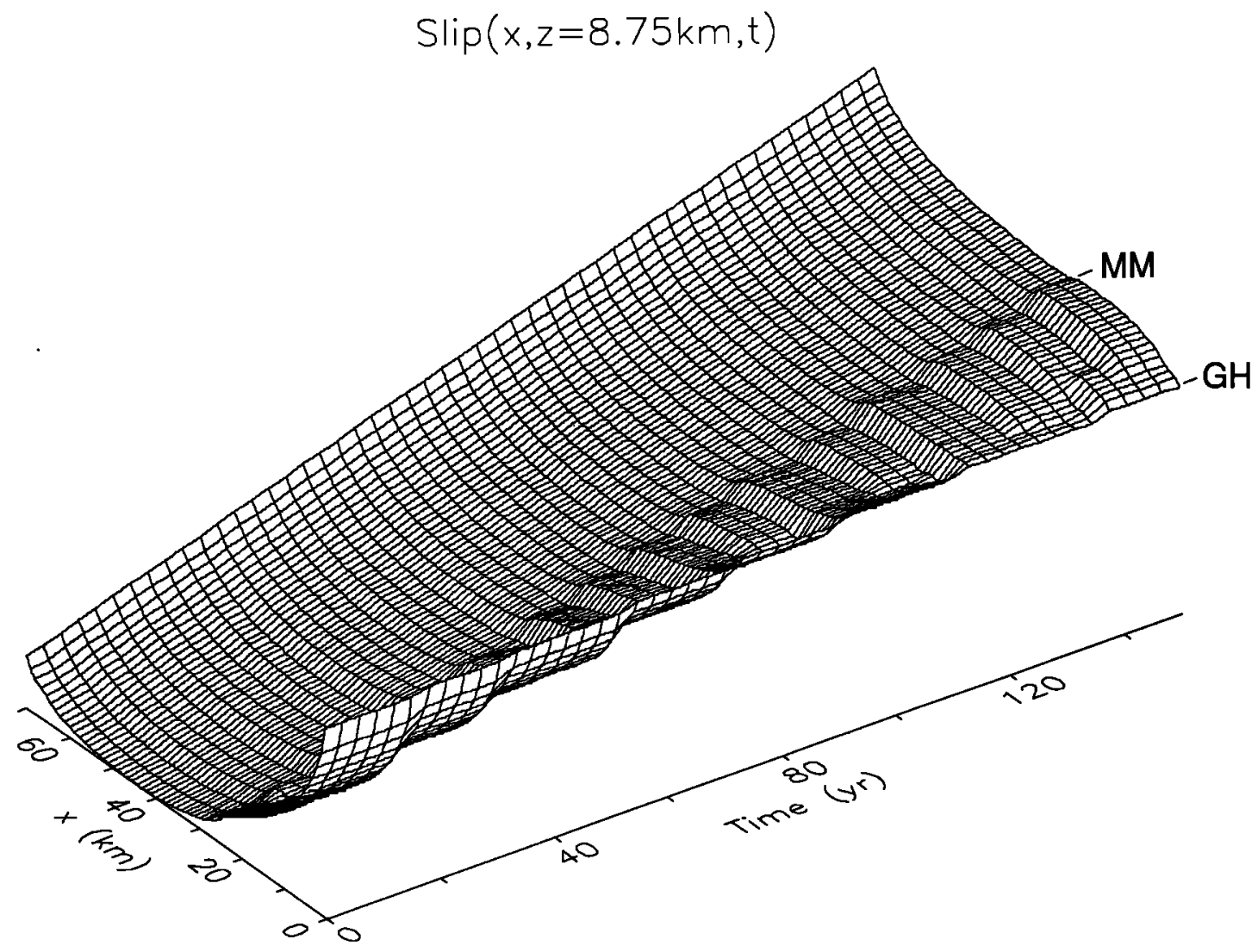

Fig. 5. Slip at a fixed (mid upper crust) depth of $8.75 \mathrm{~km}$ as a function of distance along the SAF and time. In the asperity region slip is accommodated by large steps. In the nonasperity region slip is more or less continuous. The assumed distribution of $\tau_{\mathrm{s}}$ and $\tau_{\mathbf{a}}$ is the same as in Figure 4. Slip values are normalized to the range $0-1$. 


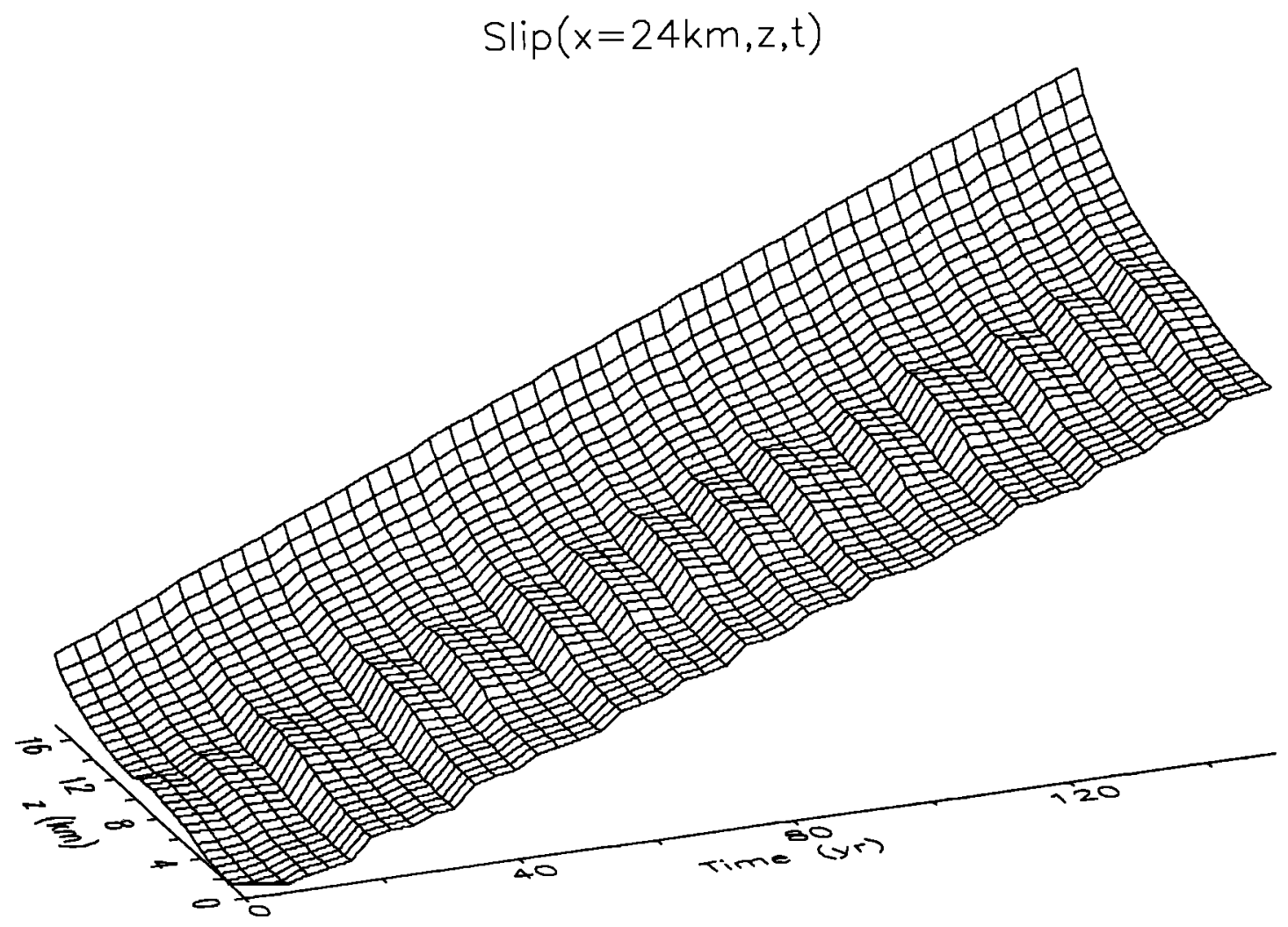

Fig. 6a. Slip as a function of depth and time at $\mathrm{x}=24 \mathrm{~km}$, near the boundary between the asperity and nonasperity regions. In the depth section corresponding to the asperity slip is accommodated by large steps; slip becomes more continuous in the shallower and deeper sections. The assumed distribution of $\tau_{\mathbf{s}}$ and $\tau_{\mathbf{a}}$ is the same as in Figure 4. Slip values are normalized to the range 0-1.

$$
\operatorname{Slip}(x=45 \mathrm{~km}, z, t)
$$

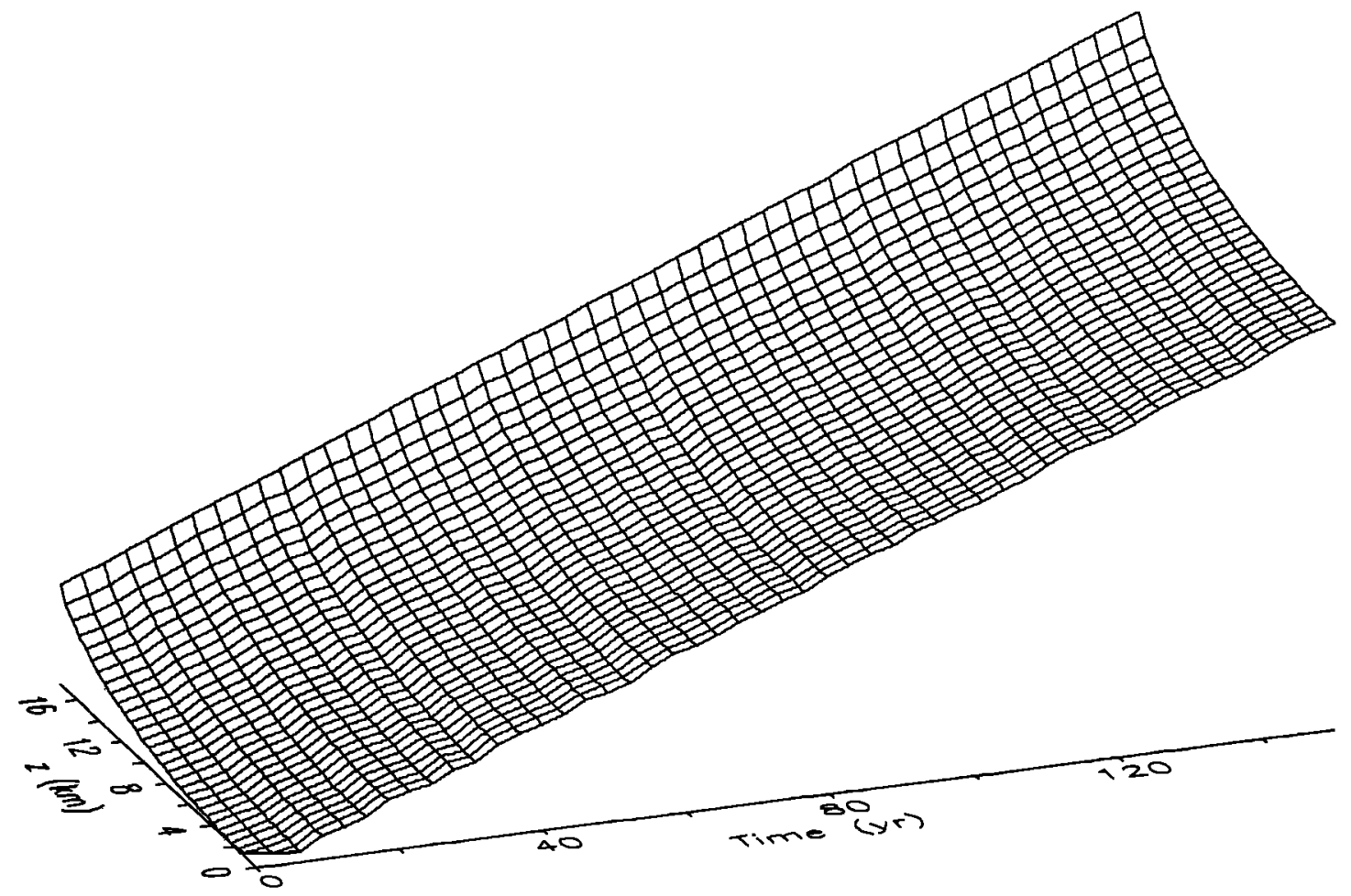

Fig. $6 b$. Same as Figure $6 a$ for $\mathrm{x}=45 \mathrm{~km}$. Here slip is more or less continuous at all depths. 
be concentrated near the edge of the Parkfield asperity. We note that the absolute values of $\tau_{\mathrm{s}}, \tau_{\mathrm{d}}$, and $\tau_{\mathrm{a}}$ play no role in our simulations; the model calculations are based only on the assumed stress drops.

The stress transfer along the fault due to incremental tectonic loadings and failing grid cells is written as a discretized form of a boundary integral equation,

$$
\tau(i, j)=-\sum_{\mathbf{k}, 1} K(i, j, k, l) \Delta u(k, l)
$$

where $\Delta u(k, l)$ is right-lateral slip at a fault patch $(k, l)$, and the stress transfer function $K(i, j, k, l)$ can be extracted from the static solution of Chinnery [1963] for dislocations in a 3-D elastic half-space. The indexes $k$ and $l$ in (2) cover the entire $x-z$ fault plane, i.e., both the upper crust layer and the lower crust - upper mantle region. A more convenient form can be written by noting that the assumed right-lateral stable sliding $V_{\mathrm{pl}} t$ at the lower crust and upper mantle region is mathematically equivalent to a left-lateral slip ( $\left.-V_{\mathrm{pl}} t\right)$ at the upper crust layer [e.g., Savage and Prescott, 1978]. This can be seen by writing the slip everywhere as $\Delta u(k, l)=\left[\Delta u(k, l)-V_{\mathrm{pl}} t\right]+V_{\mathrm{pl}} t$. The square bracket term is zero in the lower crust and upper mantle region, while the term $V_{\mathrm{pl}} t$ combines in the upper layer and lower crust - upper mantle region to give a uniform block motion that produces no stress. Thus the stress at cell $(i, j)$ can be written as

$$
\tau(i, j)=\sum_{k, l} K(i, j, k, l)\left[V_{\mathrm{pl}} t-u(k, l)\right]
$$

where now $u(k, l)$ is the total displacement of cell $(k, l)$ in the upper layer and $K(i, j, k, l)$ is Chinnery's stress transfer solution for a unit slip over a rectangular patch (the appropriate expressions for a finite rectangular dislocation patch were provided by T. E. Tullis and W. D. Stuart, written communication, 1992). The source dislocation (square bracket) term in (3) is the slip deficit of cell $(k, l)$ with respect to the long-term plate position. This is also called the "offset-phase" in the formulation of Rundle [1988].

The evolution of stress and displacement fields in the computational region is calculated using the following quasi-static procedure:

Step 1. Lock the fault by setting everywhere $\tau_{\mathrm{f}}(i, j)=\tau_{\mathrm{s}}$, where $\tau_{\mathrm{f}}(i, j)$ is the strength (failure envelope) at cell $(i, j)$.

Step 2. Increase the plate position, $V_{\mathrm{pl}} t$, so as to induce

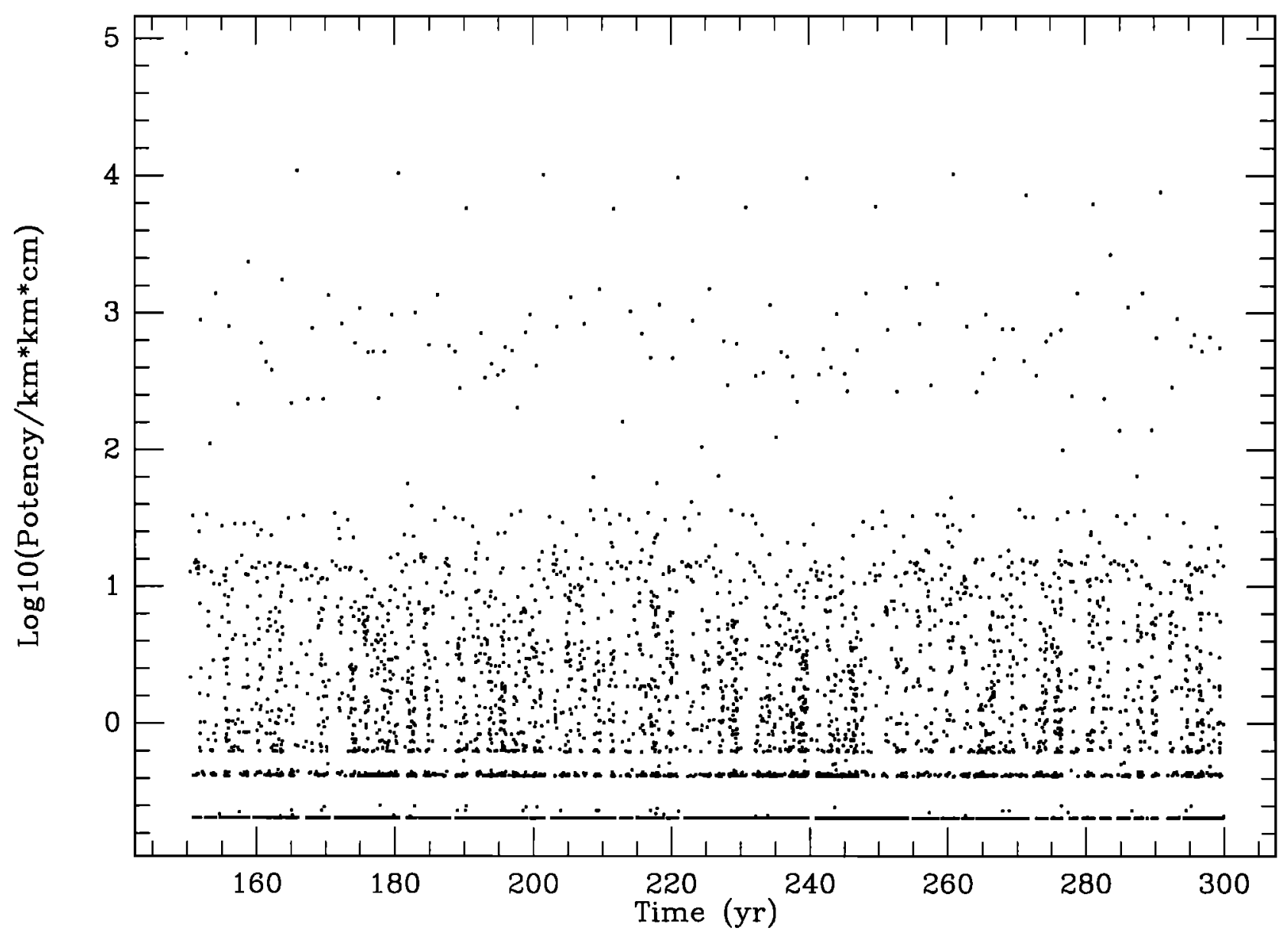

Fig. 7. Potency release in the region $0 \leq \mathrm{x} \leq 30 \mathrm{~km}, 0 \leq \mathrm{z} \leq 17.5 \mathrm{~km}$. 
failure at a single cell, i.e., start all failure episodes with a single initiator (hypocenter). We note that this is different from what is sometimes done in cellular automata and block-spring simulations where the plate position is updated by a constant increment $V_{\mathrm{pl}} \Delta t$ so that failure episodes may begin with many hypocenters.

Step 3. Find new equilibrium configuration of the fault as follows:

Step 3.1. Calculate 3-D elastic stress $\tau(i, j)$ along the fault using equation (3).

Step 3.2. Compare stress $\tau(i, j)$ with the failure envelope $\tau_{\mathrm{f}}(i, j)$. For subset of cells having $\tau \geq \tau_{\mathrm{f}}$ (denoted as the rupture set \{\}$_{r}$ ) implement steps 3.2.1 - 3.2.4:

Step 3.2.1. Solve for slip $\{\Delta u\}_{\mathrm{r}}$ via $\{\Delta \tau\}_{\mathrm{r}}=\{\tau(i, j)-$ $\left.\tau_{\mathrm{a}}(i, j)\right\}_{\mathrm{r}}=\{K(i, j, i, j) \Delta u(i, j)\}_{\mathrm{r}}$, where $K(i, j, i, j)$ is the self-stiffness of cell $(i, j)$.

Step 3.2.2. Update displacements $\{u\}_{\mathrm{r}}$.

Step 3.2.3. Reduce strengths to dynamic levels $\left\{\tau_{\mathrm{f}}\right\}_{\mathrm{r}}$ $=\left\{\tau_{\mathrm{d}}\right\}_{\mathrm{r}}$.

Step 3.2.4. Write output; check exit criteria (number of time steps or analysis years).

Step 3.3. Check the number of elements $N$ in the set \{\}$_{\mathrm{r}}$. If $N>0$, the rupture still propagates; go to step 3.1 . If $N=0$, the fault is at equilibrium; go to step 1 .

Steps 3.1 to 3.3 amount to solving the matrix equation $\left\{\tau-\tau_{\text {final }}\right\}_{\mathrm{r}}=\{K\}_{\mathrm{r}}\{\Delta u\}_{\mathrm{r}}$ by an iterative procedure, where the final stress values $\tau_{\text {final }}(i, j)$ are distributed between $\tau_{\mathrm{d}}(i, j)$ and $\tau_{\mathrm{a}}(i, j)$ as discussed above.
In an earlier version of our algorithm, each cell whose stress was found to be at or above the failure threshold slipped toward a stress level $\tau_{\mathrm{a}}$ during the scanning procedure, i.e., step 3.2.1 was done inside step 3.2. In this early version the precise values of stress drops and stress transfers depend on the scanning order, in contrast to the algorithm outlined above. We note, however, that for the choice of parameters used in our study (see next section) the results obtained during trial runs by the different algorithms were essentially the same. Our simulation procedure generates large ruptures as aggregates of small subevents on quasi-independent fault segments, on each of which there are initiation, propagation, and arrest events and possible reinitiations or repeated reinitiations. The most important model parameters are the number and size of grid cells; the location, size, and shape of the asperity, i.e., the distributions of $\tau_{\mathrm{s}}, \tau_{\mathrm{d}}$, and $\tau_{\mathrm{a}}$; and the recurrence interval and failure timing of the 1857 and 1906 patches. It is interesting to note that the above description of rupture process is similar to what is simulated by the barrier model of Papageorgiou and Aki [1983].

\section{RESULTS}

\section{A Circular Crack in a Full Space}

In order to test our algorithm we begin with a simple case for which the algorithm-generated slip can be compared with an exact result. A fault surface that is $100-\mathrm{km}$-long and $100-\mathrm{km}$-deep is loaded by 150 years of plate motion,

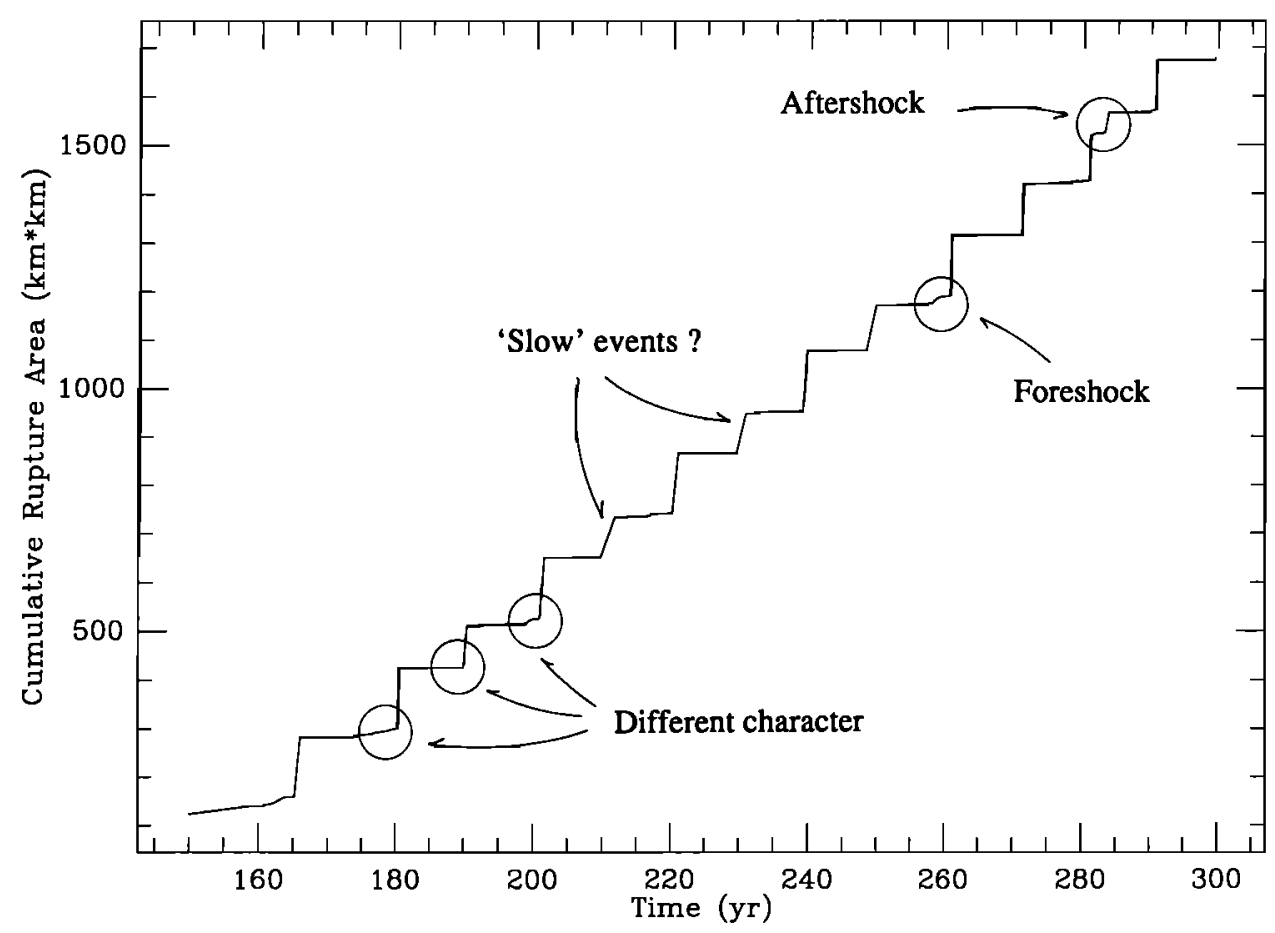

Fig. 8. Cumulative rupture area at the Parkfield asperity region. Note the diversity in the character of the large events. 
i.e., $V_{\mathrm{pl}} t=35 \mathrm{~mm} / \mathrm{yr} \times 150$ years $=5.25 \mathrm{~m}$. A circular crack region with radius of $10 \mathrm{~km}$ and origin at the center of the fault is allowed to slip so as to relieve the stress generated there by the plate motion. Figure 3 shows slip surfaces calculated using an analytical solution for a circular crack in a full space [Dmowska and Rice, 1986, equation 3.2.13] and our dislocation-based algorithm. The agreement between the analytical solution and the numerical result, obtained using $100 \times 100$ dislocation patches, is very good; calculated slip values at the edge and center of the crack differ by $1 / 8$ and $1 / 250$, respectively.

Homogeneous Asperity and Nonasperity Regions With Strongly Differing Stress Drops

As a first realization of the SAF model of Figure 1 we set $\tau_{\mathrm{s}}=40$ bar ( $4 \mathrm{MPa}$ ) and consider a uniform strength asperity in the region $0 \leq x \leq 25 \mathrm{~km}, 5 \leq z \leq 10 \mathrm{~km}$. The asperity is characterized by $\tau_{\mathrm{a}}=0.1 \tau_{\mathrm{s}}$, while in the nonasperity region, $\tau_{\mathrm{a}}=0.9 \tau_{\mathrm{s}}$, i.e., the transient stress drops in the asperity and nonasperity regions are 36 bars and 4 bars, respectively. Here and in the following section we use $128 \times 32=4096$ square cells having a dimension of about $550 \mathrm{~m}$. This is close to the size of the slip patches (dimension of about $200 \mathrm{~m}$ ) that generate repeated microearthquakes at Parkfield [Antolik et al., 1991]. We begin all simulations with 150 years of model-conditioning analysis during which the 1857 and 1906 earthquake

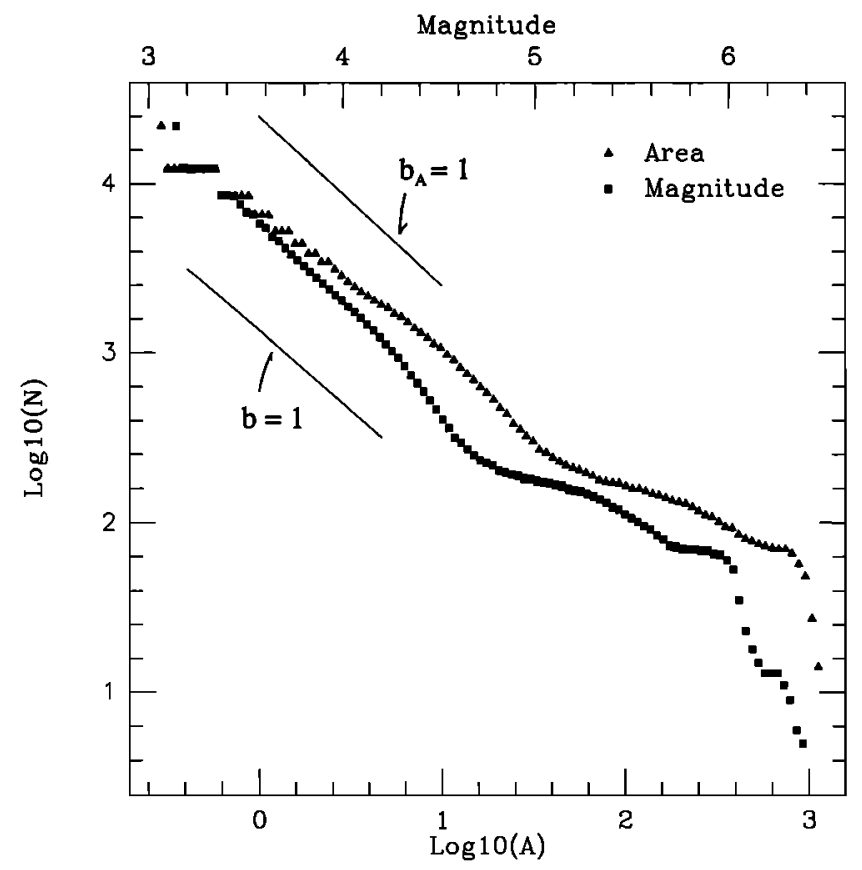

Fig. 9. Cumulative frequency-size (FS) statistics of earthquake magnitude (squares) and rupture area (triangles) during 150 analysis years in the $70 \times 17.5 \mathrm{~km}^{2}$ computational region. Units of rupture area are square kilometers. For small events $b \approx$ 1 and $b_{\mathrm{A}} \approx 1$, where $b$ and $b_{\mathrm{A}}$ are based on event magnitude and rupture area, respectively. patches (regions I and IV in Figure 1) are locked and the stably sliding zones (regions III and V in Figure 1) move by the amount $V_{\mathrm{pl}} t=35 \mathrm{~mm} / \mathrm{yr} \times 150$ years $=5.25 \mathrm{~m}$. The fault configuration at the end of the model-conditioning period provides nonzero heterogeneous initial states of

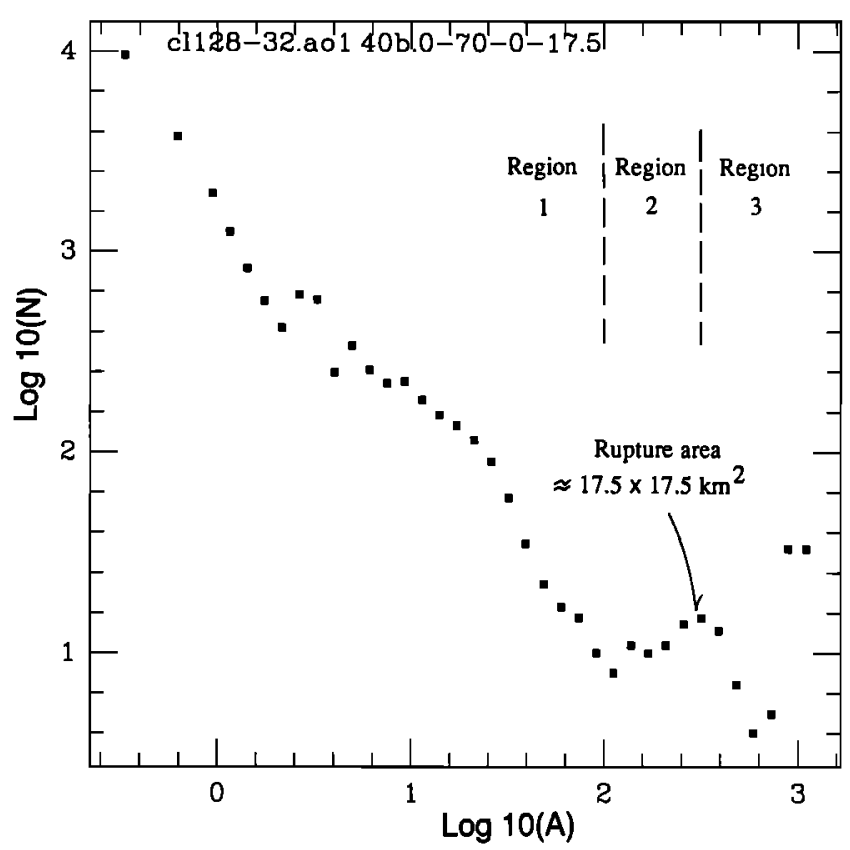

Fig. 10a. Noncumulative frequency-size (FS) statistics of rupture area during 150 analysis years in the $70 \times 17.5 \mathrm{~km}^{2}$ computational region. Region 1 is a self-similar domain with $b_{\mathrm{A}} \approx 1$; region 2 shows enhancement in frequency of intermediate size events with a peak at a rupture area having the dimension of the upper layer thickness; region 3 is a final steep decay ending with a peak for events the size of the computational grid.

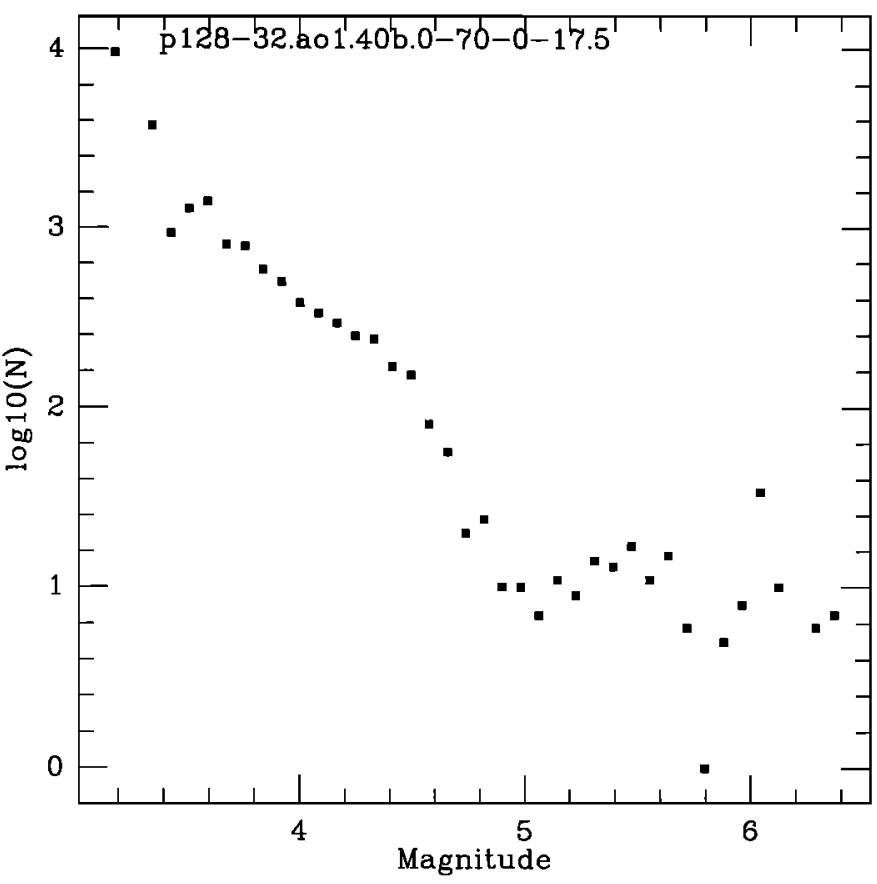

Fig. 10b. Same as Figure $10 a$ for event magnitude. 
stress and displacement for the continuing analysis. As indicated in Figure $1 b$, at $t=150^{+}$years, or more generally at $t=0^{+}$years into the analyzed earthquake cycle, we impose $5.25 \mathrm{~m}$ of right-lateral slip (equal to the accumulated plate motion in 150 years) on the 1857 and 1906 earthquake patches. For simplicity, both earthquake patches are moved simultaneously. We note that in the present modeling the computational grid is largely "shielded" from the 1906 earthquake patch by the presence of the stably sliding region III.

Figure 4 shows calculated slip distributions along the SAF at four different times. The bottom surface $\left(t=0^{-}\right)$is the slip at the end of the model-conditioning period. The other three surfaces show calculated SAF slip at $0.1,75$, and $150^{-}$years into the analyzed earthquake cycle. The big jump between the slip surfaces at $t=0^{-}$and $t=0.1$ years is due to the imposed 1857 event. We note that the asperity modeled by the assumed distributions of $\tau_{\mathrm{s}}, \tau_{\mathrm{a}}$, and $\tau_{\mathrm{d}}$ is clearly shown on the various slip surfaces. We also observe that the results of Figure 4 are compatible with geodetic measurements along the SAF; the difference between calculated slip values on the Earth's surface at $t=75$ years and $t=150^{\circ}$ years increases toward the creeping zone in agreement with the measured geodetic profile [Buford and Harsh, 1980; Lisowski and Prescott, 1981; Schultz et al., 1982].

Figure 5 shows time evolution of slip along the fault at a fixed (mid upper crust) depth of $8.75 \mathrm{~km}$. Along the first $25 \mathrm{~km}$, where the assumed asperity lies, slip is accommodated in the form of large steps separated by periods of little or no activity. This mimics or represents the recurrent $M 6$ Parkfield earthquakes. Beyond $25 \mathrm{~km}$, in the nonasperity region, slip is accommodated in a nearly continuous fashion.

Figures $6 a$ and $6 b$ show slip as a function of depth and time at fixed positions along the fault. Near the boundary between the asperity and nonasperity regions (Figure $6 a, x$ $=24 \mathrm{~km}$ ) the shallow slip is accommodated by large steps, while the deep section $(z>10 \mathrm{~km})$ experiences more or less continuous slip. On the other hand, in the nonasperity region (Figure $6 b, x=45 \mathrm{~km}$ ) the slip is more or less continuous at all depths. The results of Figures $6 a$ and $6 b$, like those of Figure 5, are compatible with geodetic data and earthquake distribution along the central SAF. We note that in our model all calculated slip occurs in the form of earthquakes; there is no aseismic slip within the computational grid.

In following figures we show and use rupture area and potency release. Rupture area is the total slipped area in given region and time. We note that the rupture area does not have to be continuous, although it typically is. Potency is the integral of slip over the ruptured area in given region and time. The potency is equal to the seismic moment divided by the rigidity; owing to the ambiguity in the definition of rigidity for fault zone spanning material contrasts [Heaton and Heaton, 1989; Ben-Zion, 1989] we prefer to use potency. For faulting in a homogeneous elastic solid as here, with $\mu=30 \mathrm{GPa}$, potency $P$ of $10^{4}$ $\mathrm{km}^{2} \mathrm{~cm}$ corresponds, for example, to a moment of $3 \times$ $10^{18} \mathrm{~N} \mathrm{~m}=3 \times 10^{25}$ dyn $\mathrm{cm}$.

Figure 7 shows potency release in the fault region $0 \leq x$ $\leq 30 \mathrm{~km}, 0 \leq z \leq 17.5 \mathrm{~km}$ as a function of time. The results suggest two large (about $10^{4} \mathrm{~km}^{2} \mathrm{~cm}$ ) alternating values of potency release. The alternating pattern is, however, not periodic, and it does not persist throughout the entire 150 years of model analysis. We note that there are two bands of potency release values, around $10^{2}$ and $10^{3.6} \mathrm{~km}^{2} \mathrm{~cm}$, that characterize only a small number of events. As explained below, the relative deficiency in the number of events releasing potency in these zones is a direct consequence of our 3-D elastic stress transfer calculations.

Figure 8 shows cumulative rupture area along the asperity region $0 \leq x \leq 25 \mathrm{~km}, 5 \leq z \leq 10 \mathrm{~km}$. We note the diversity and different character of the large events. The event at about 180 years is preceded by a period of gradual rupture formation; the events at about 190, 220, and 240 years are abrupt; the events at about 210 and 230 years resemble "slow" earthquakes; the events at about 200 and 260 years are preceded by "foreshocks"; and the event at about 280 years is followed by an "aftershock". It may thus be unrealistic to expect simple precursory patterns, such as accelerated microearthquake slip, to occur before the failure of a Parkfield-type asperity. Although such patterns occur before some failures, they are not very indicative.

Figure 9 shows cumulative frequency-size statistics of rupture area and earthquake magnitude in the computational grid $0 \leq x \leq 70 \mathrm{~km}, 0 \leq z \leq 17.5 \mathrm{~km}$ during the 150 analysis years. The earthquake magnitudes $M$ are obtained using the relation $M=(2 / 3) \log (P)+3.6$, where $P$ is potency in square kilometers times centimeters (the units of rupture area in all figures showing FS statistics are square kilometers; $\log =\log _{10}$ ). The above expression follows from the moment-magnitude relation of Hanks and Kanamori [1979], $\log \left(M_{0}\right)=(3 / 2) M+16.1$, where $M_{0}=$ $\mu P$ is seismic moment in dyn centimeters, upon using a nominal rigidity $\mu=30 \mathrm{GPa}\left(3 \times 10^{11} \mathrm{dyn} / \mathrm{cm}^{2}\right)$ and accounting for the change in units. There are three clear event groups in Figure 9: small events characterized by $b \approx$ 1.2 and $b_{\mathrm{A}} \approx 1$, intermediate size events having $b, b_{\mathrm{A}}<$ 0.5 , and a final steep falloff. A Gutenberg-Richter region $b$, $b_{\mathrm{A}} \approx 1$ is commonly observed and simulated, indicating that small events are self-similar. The intermediate region results from a supercritical rupture growth beyond certain rupture area and potency release thresholds. This is better seen in Figures $10 a$ and $10 b$ where we show noncumulative FS statistics. The small events fall more or less on selfsimilar GR curves, but beyond a rupture area of about $\mathbf{8 0}$ 
$\mathrm{km}^{2}$ (Figure $10 a$ ) or a magnitude of about 5 (Figure $10 b$ ) by either the upper layer thicknew to a size that is limited the entire model dimer thickness $\left(\approx 17.5 \times 17.5 \mathrm{~km}^{2}\right)$ or ruptures that release are usually unstoppable. The than a threshold value understood in terms osults can be stress concentrated in the uniformly greater than forder cells of the failed region is discussion part of the paper.

\section{Additional Cases of Assumed Stress Drop Distributions}

The asperity of the previous section simulates a strong and abrupt property variation along the SAF. The resulting displacement field is in general agreement with geodetic and seismic observations. The average recurrence time of the simulated Parkfield earthquakes is, however, about 13 Mears, shorter than the 22-year estimate of Bakun and
McElly [1984]. In this section increasingly more we examine a few cases representing Parkfield earthquake faults. In order to get an average observations we set $\tau$ recurrence time closer to the assumed stress drop $\tau_{s}=60$ bars. We consider five cases of the previous distributions. (1) The distribution of fluctuations, uncorren with $\pm 0.1 \tau_{\text {s }}$ random stress drop order to reduce the from cell to cell (Figure 11a) (In average transient sthe computation time we increase the

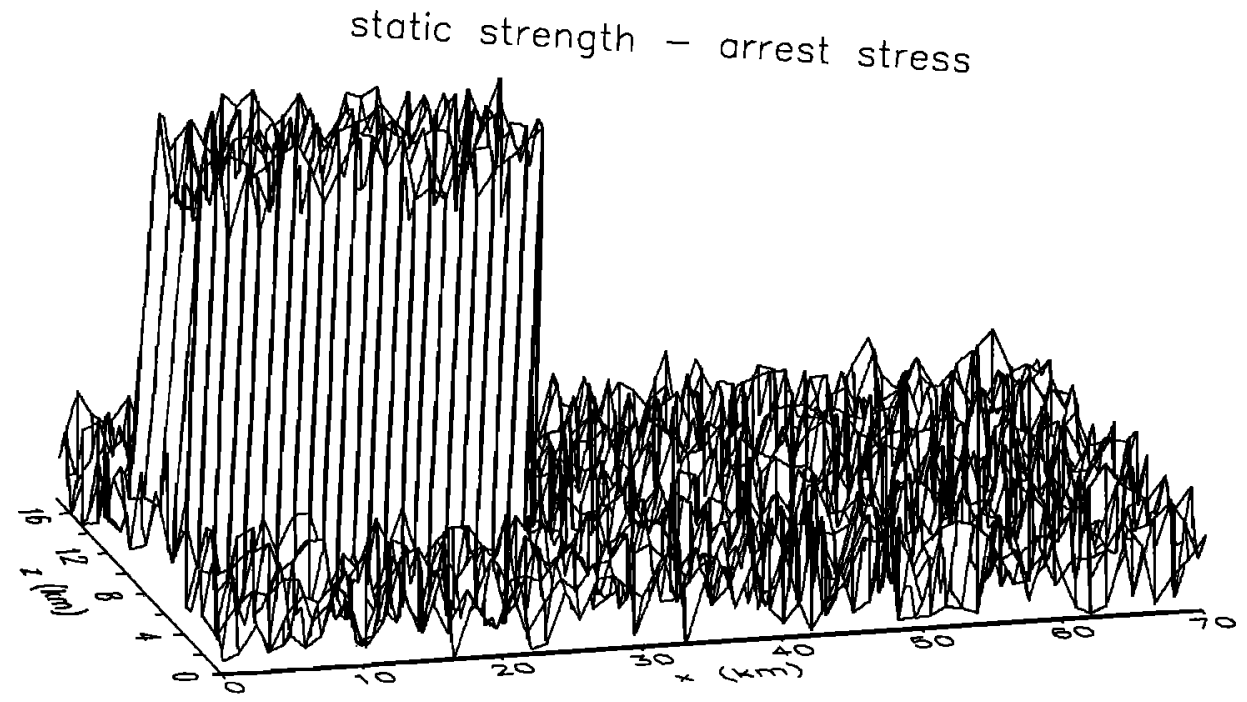

Fig. 11a. Assumed stress drop distributid uncorrelated random property variation along the fault. The amplitude of the rest stress is $\tau_{\mathrm{a}}=0.1 \tau_{\mathrm{s}}$. In the nonasperity regiongth is $\tau_{\mathrm{s}}=60$ bars. In the asperity The random fluctuations is $0.1 \tau_{\mathrm{s}}$.

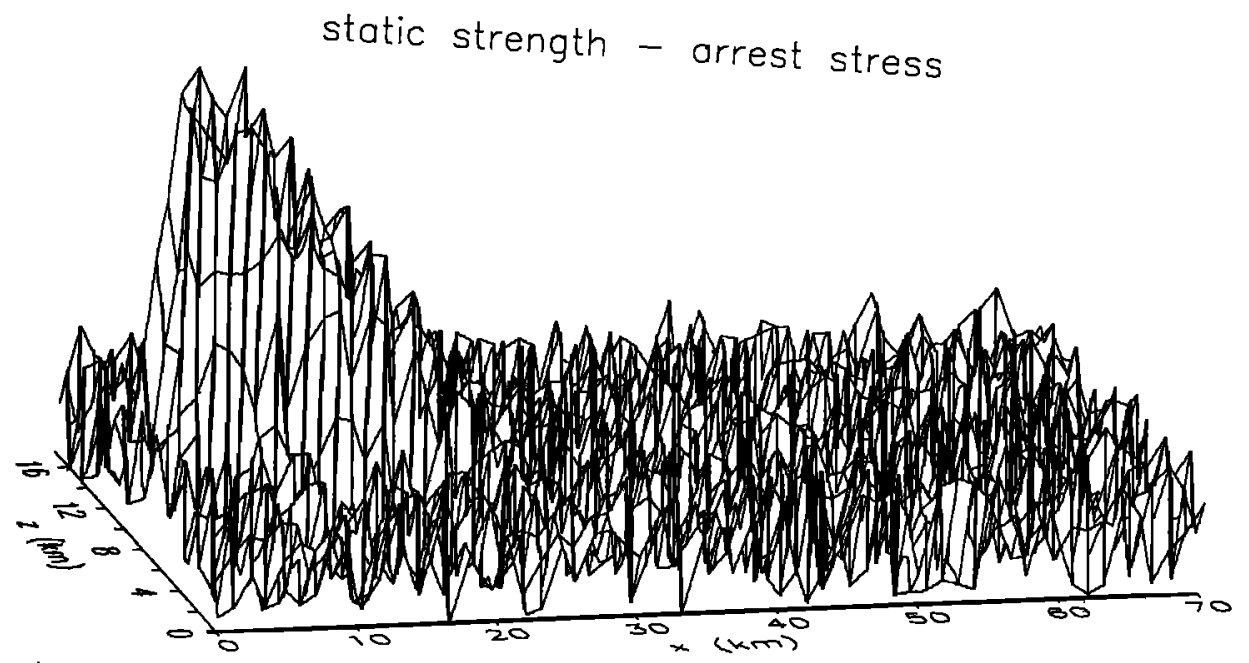

Fig. $11 b$. Assumed stress drop distribution for asperity anto

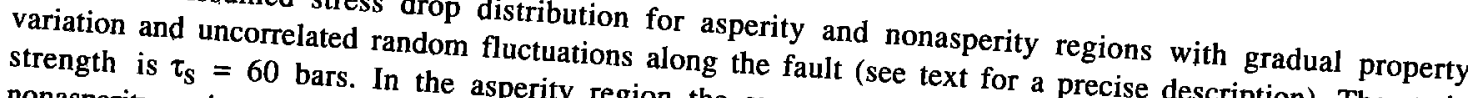
nonasperity region the av. In the asperity region the average minimum artest ctress is $\tau_{\mathrm{a}}=0.8 \tau_{\mathrm{s}}$. The amplitude of the random fluctuations $\tau_{\mathrm{a}}=0.1 \tau_{\mathrm{s}}$. In the 
$0.2 \tau_{\mathrm{s}}$, setting there $\tau_{\mathrm{a}}=[0.8 \pm 0.1] \tau_{\mathrm{s}}$. The average transient stress drop in the asperity region remains $0.9 \tau_{\mathrm{s}}$.), (2) a gradual property transition between the asperity and nonasperity zones (In the asperity region $(0 \leq x \leq 25,5 \leq z$ s 10) $\tau_{\mathrm{a}}=\{0.1+\operatorname{Max}[0.7 x / 25,0.7 \operatorname{Abs}(z-7.5) / 2.5]\} \tau_{\mathrm{s}}$, where Max and Abs denote, respectively, maximum and absolute values. In the nonasperity region, $\tau_{\mathrm{a}}=0.8 \tau_{\mathrm{s}}$ ), (3) the distribution of the previous case with $\pm 0.1 \tau_{\mathrm{s}}$ uncorrelated random stress drop fluctuations (Figure 11b), (4) a homogeneous $0.2 \tau_{\mathrm{s}}$ transient stress drop along the fault, and (5) same as case 4 with $\pm 0.1 \tau_{\mathrm{s}}$ uncorrelated random fluctuations.

Figures $12 a-12 c$ show time evolution of slip along the $\mathrm{SAF}$ at a depth of $8.75 \mathrm{~km}$ for the stress drop distribution cases 1,3 , and 5 above. The results for cases 2 and 4 (not shown) are similar to those of 3 and 5 , respectively. We note that as the fault properties become increasingly more uniform, the resulting displacement field becomes less compatible with what is observed along the SAF. In particular, the results of Figure $12 c$ indicate that the mere proximity to the 1857 rupture zone is not sufficient to generate a Parkfield-type asperity. The mean and sample standard deviation of the simulated Parkfield earthquakes recurrence time in Figure $12 a$ (strong property variation along the fault) are about 19 and 3 years, respectively. The maximum and minimum time intervals between the Parkfield-type earthquakes in Figure $12 a$ are, respectively, 24 and 15 years. These numbers are similar to values given by Bakun and McEvilly [1984], although the spread and standard deviation are smaller than figures based on their earthquake catalog as indicated by Ben-Zion et al. [1993, Table 2].

Figures $13 a-13 e$ show frequency-size statistics of rupture area and event magnitude for the various assumed stress drop distributions. Inspection of these figures shows that the general structure of the FS data discussed in the previous section is preserved. In particular, the simulations are robust in having peaks for events with rupture areas having the size of the elastic layer thickness (i.e., rupture area $\approx 17.5 \times 17.5 \mathrm{~km}^{2}$ ) or the whole system. The incorporation of random fluctuations in the model fault properties results in a strong smoothing effect on the obtained frequency-size relations. This is seen by comparing Figure $13 a$ to Figure 9 (strong property variation along the fault, with and without random fluctuations), Figure $13 c$ to Figure $13 b$ (gradual property variation along the fault, with and without random fluctuations), and Figure $13 e$ to Figure $13 d$ (uniform fault properties, with and without random fluctuations). A lesser smoothing effect results from an overall increase in model



Fig. 12a. Slip at a fixed (mid upper crust) depth of $8.75 \mathrm{~km}$ as a function of distance along the SAF and time for the stress drop distribution of case 1 (Figure $11 a$ ). Slip values are normalized to the range $0-1$. 


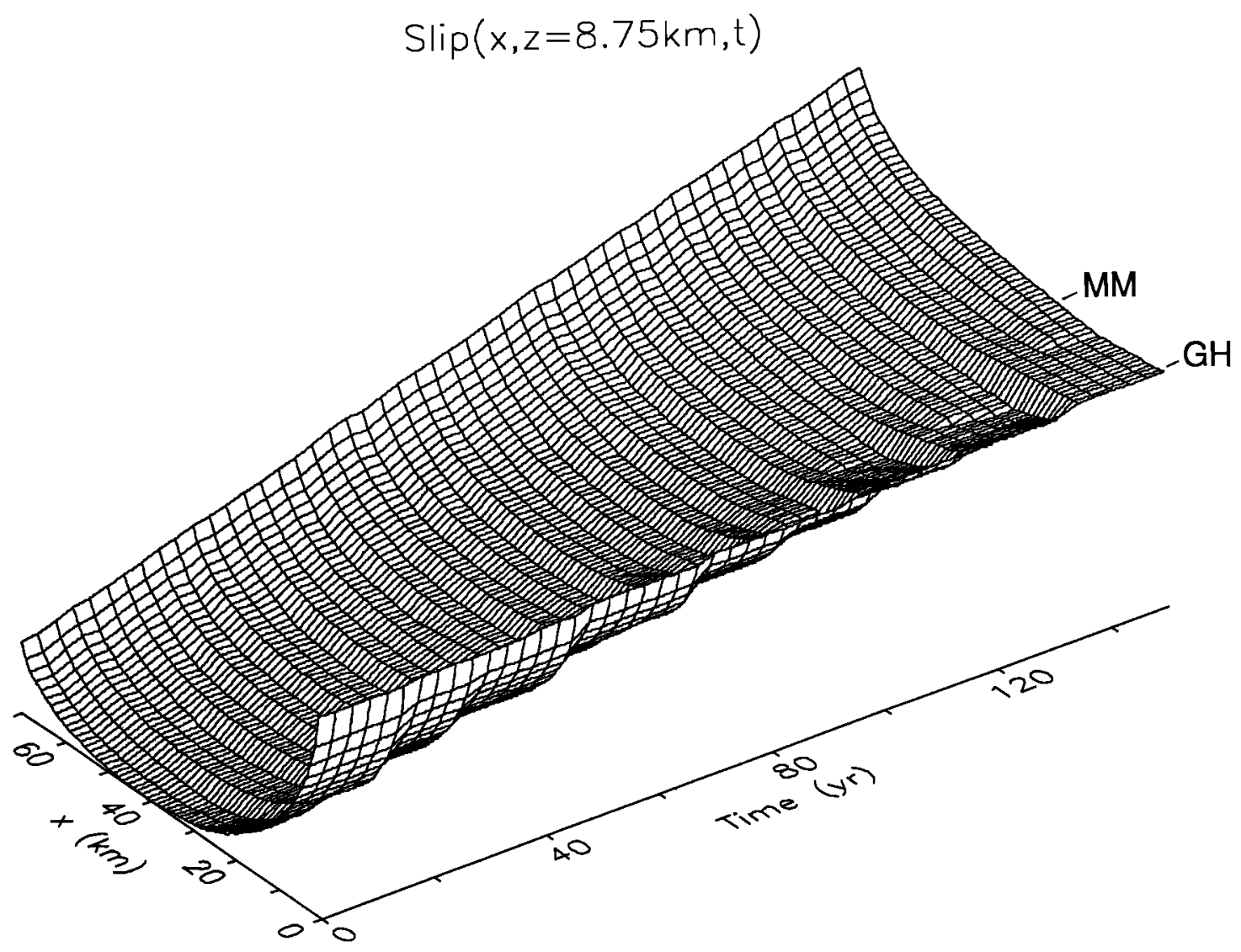

Fig. 12b. Same as $12 a$ for the stress drop distribution of case 3 (Figure $11 b$ ).

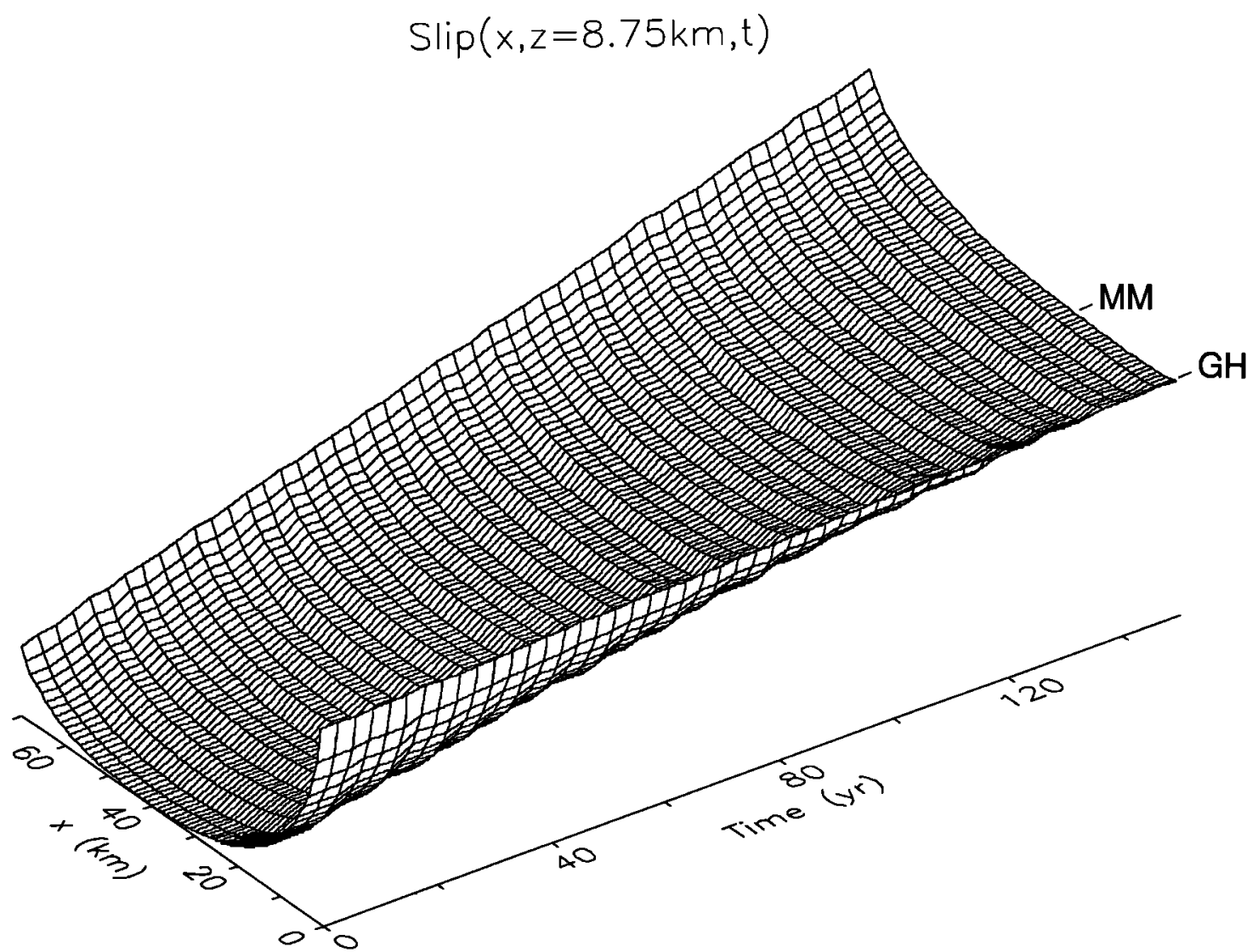

Fig. $12 c$. Same as $12 a$ for the stress drop distribution of case 5 (uniform $\tau_{\mathrm{s}}$ and $\tau_{\mathrm{a}}$, with superposed random fluctuations). 


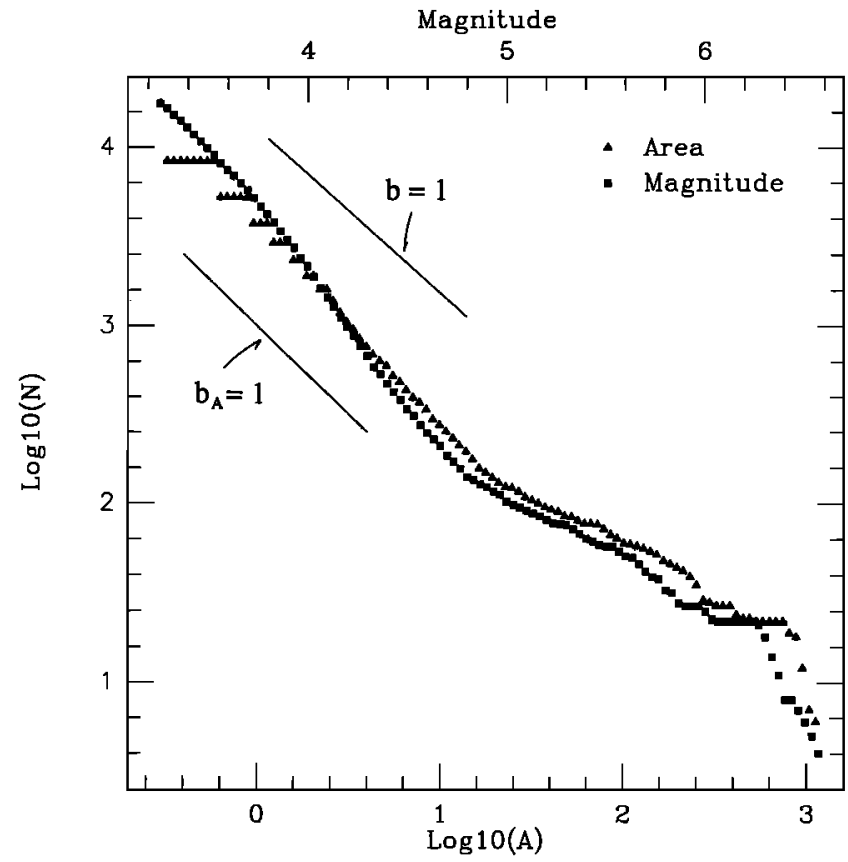

Fig. 13a. Cumulative FS statistics of earthquake magnitude (squares) and rupture area (triangles) for the stress drop distribution of case 1 (Figure $11 a$ ).

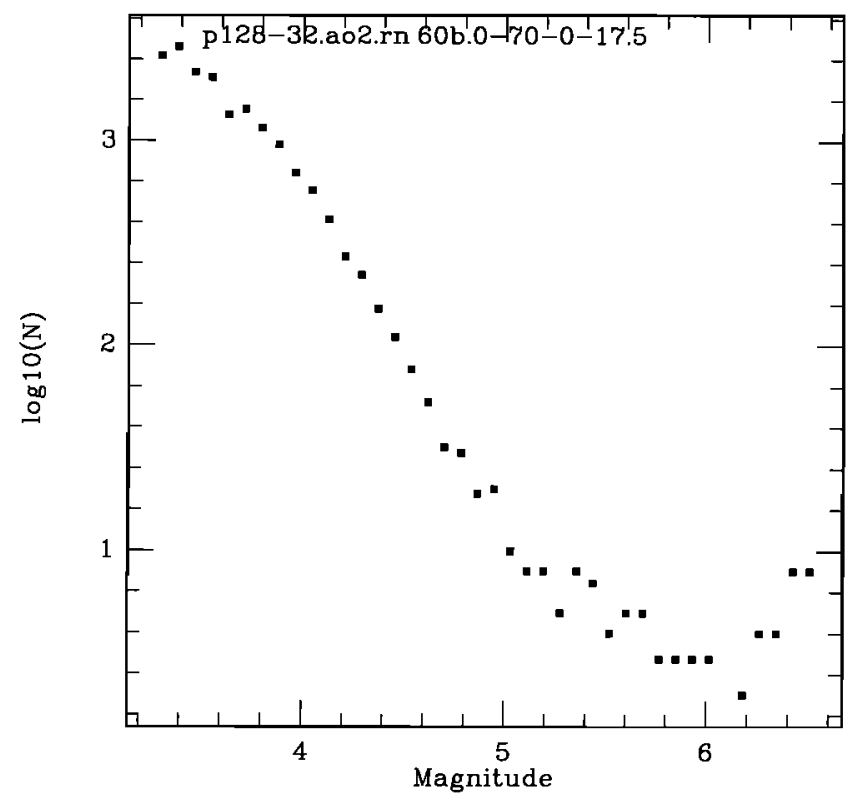

Fig. 13c. Noncumulative FS statistics of earthquake magnitude for the stress drop distribution of case 3 (Figure $11 b$ ).

uniformity, e.g., compare Figure $10 b$ (strong property variation along the fault) with Figure $13 b$ (gradual fault property variation), and Figure $10 a$ (strong property variation along the fault) with Figure $13 d$ (uniform fault properties). The average $b$ and $b_{\mathrm{A}}$ values of the initial selfsimilar regions in the various model realizations are about 1.2 and 1 , respectively.

\section{DISCUSSION}

We perform 3-D numerical simulations of fault instabilities using a model incorporating both large-scale

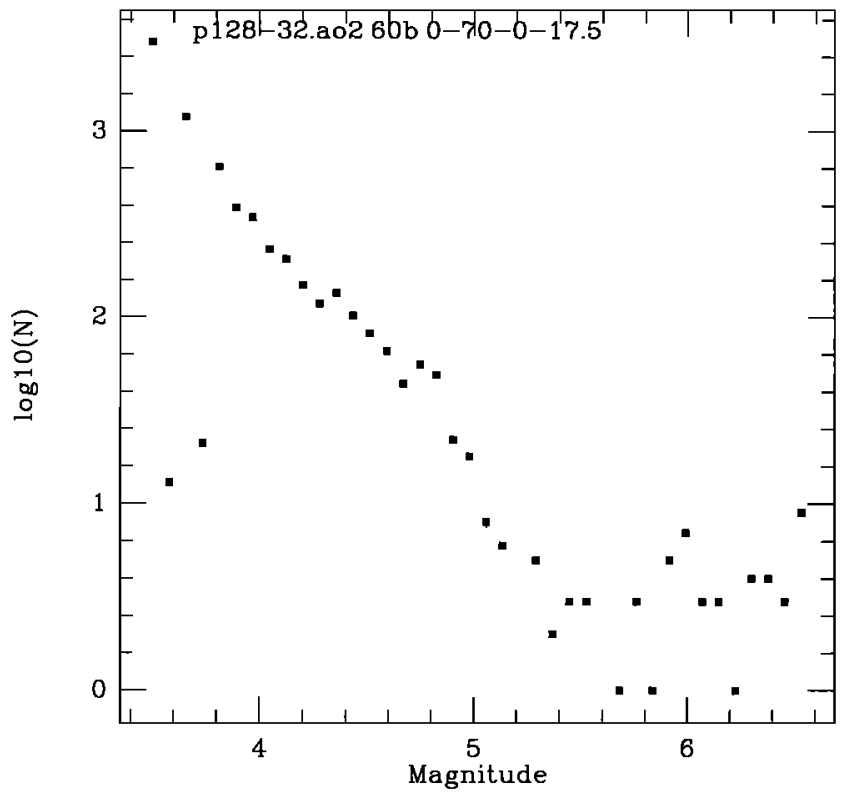

Fig. 13b. Noncumulative FS statistics of earthquake magnitude for the stress drop distribution of case 2 (like Figure $11 b$ but without random fluctuations).

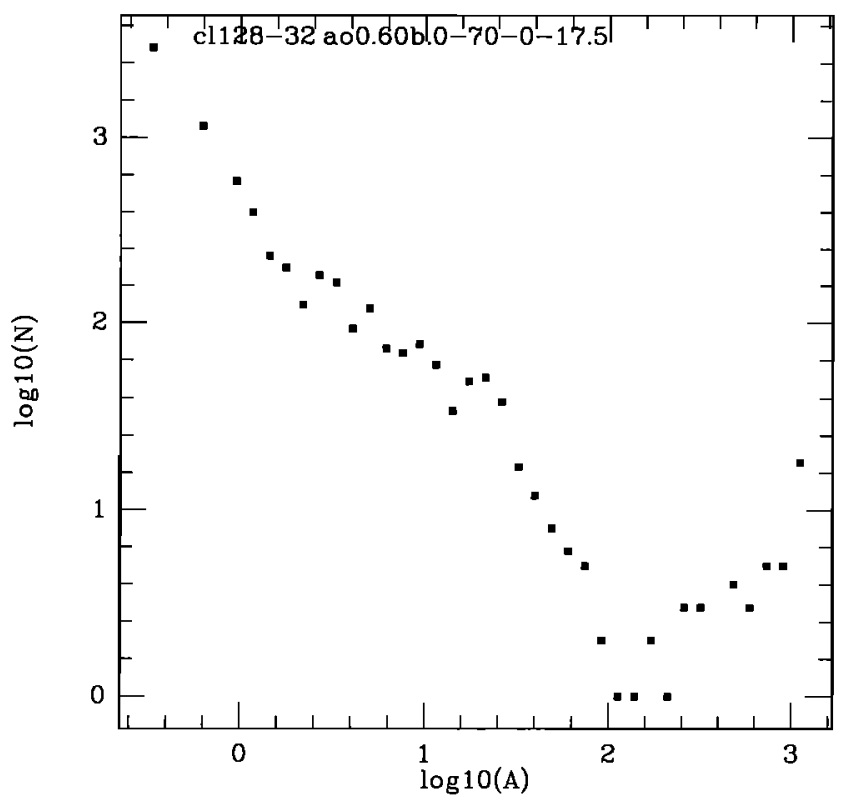

Fig. 13d. Noncumulative FS statistics of rupture area for the stress drop distribution of case 4 (uniform $\tau_{\mathrm{s}}$ and $\tau_{\mathrm{a}}$ ).

mechanical regimes and small-scale fault heterogeneities. The model is tailored in present application to the central SAF. Imposed slip boundary conditions represent the great 1857 and 1906 rupture zones, the creeping segment of the central SAF, and a stably sliding region in the lower crust and upper mantle. Assumed distributions of stress drops on a computational region to the $\mathrm{NW}$ of the 1857 rupture zone model small-scale fault heterogeneities (wavelengths associated with the used cell size and with larger scale of the Parkfield asperity). The computational cells are governed by static/kinetic frictions. Our model is thus 


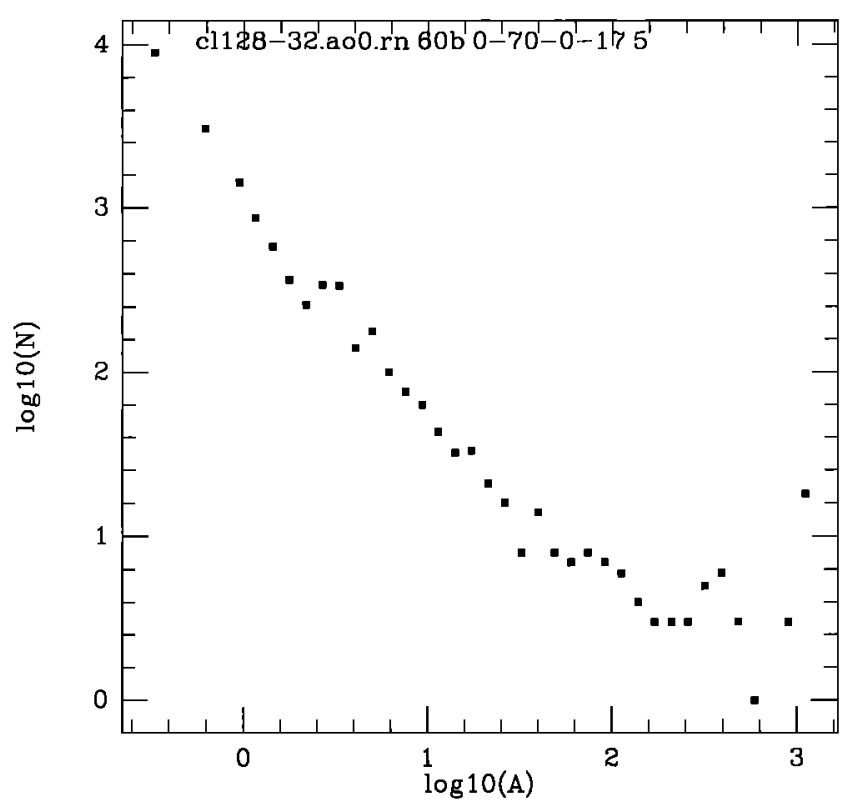

Fig. 13e. Noncumulative FS statistics of rupture area for the stress drop distribution of case 5 (uniform $\tau_{\mathrm{s}}$ and $\tau_{\mathrm{a}}$, with superposed random fluctuations).

inherently discrete, corresponding to a situation in which the characteristic size of geometric disorder within the fault (represented by cell size, here a few hundreds of meters) is much larger than the nucleation size of slip instabilities (of the order of tens of centimeters to tens of meters for $L=5$ to $500 \mu \mathrm{m}$ ) based on slip weakening or rate- and statedependent friction laws [Rice, 1993]. In the current work, only simple stress drop distributions are assumed. Other distributions, modeling more realistic (e.g., fractal) smallscale fault heterogeneities, can be incorporated easily in future work.

In the absence of a characteristic distance in the used friction law it is not clear how to rationalize a criterion for "small enough" numerical cells. Both the number and size of the used cells are important model parameters. From a numerical point of view, a large number of cells (a large number of degrees of freedom) is necessary for preventing the model from falling into an unrealistically simple periodic behavior after a relatively short model time (e.g., $10^{2}-10^{4}$ years; Rundle [1988]). Apparently, our simulation procedure could, in principle, lead to a complex periodic solution regardless of the number of used cells, if the model employs periodic boundary conditions (note that the boundary conditions in the present work are not periodic) and the model is run unchanged (i.e., with the same failure mechanism and stress drop distribution) for a "long enough" time (e.g., $10^{6}$ years; Narkounskaia et al. [1992]; G. Narkounskaia, personal communication, 1992; A. Gabrielov et al., manuscript in preparation, 1993). From a physical point of view, the seismological observations of Antolik et al. [1991] (repeated microearthquakes at Parkfield), Sacks and Rydelek [1992] (flattening of FM curves and strong variation of stress drops for small earthquakes), Malin et al. [1989] (flattening of FM curve for small earthquakes at Parkfield), Hough et al. [1992] (strong variation of stress drops of small events), and Leary and Ben-Zion [1992], Hough et al. (manuscript in preparation, 1993), and Ben-Zion [1993] (modeling of fault zone trapped and head waves) suggest that a proper cell size for the central SAF may be of the order of a few hundreds of meters.

In practice, the number of cells used is limited by the available computing facility. Using a Sun Sparc Station 2, we modeled a $70 \times 17.5 \mathrm{~km}^{2}$ fault region with $128 \times 32=$ 4096 square cells having a dimension of about $550 \mathrm{~m}$. To verify that our results are stable with respect to further reduction in cell size, we repeated the calculations for the stress drop distribution of Figure $11 a$, using $160 \times 40=$ 6400 cells. The resulting FS statistics (Figure 14) are similar to what is obtained with our standard 4096 cells (Figure 13a). As is shown below, however, the range of self-similarity in the simulated FS statistics shifts to lower magnitudes as the cell size is reduced.

One of the most commonly discussed parameters of observed and simulated seismicity is the $b$ value of the frequency-size statistics. It is important to distinguish in both model and data between a system consisting of many different faults and a system representing a single fault or a collection of similar faults. Pacheco et al. [1992] fitted global FM data (a system with many different faults) with two straight lines having $b \approx 1$ and $b \approx 1.5$ for small and large earthquakes, respectively. This result was anticipated

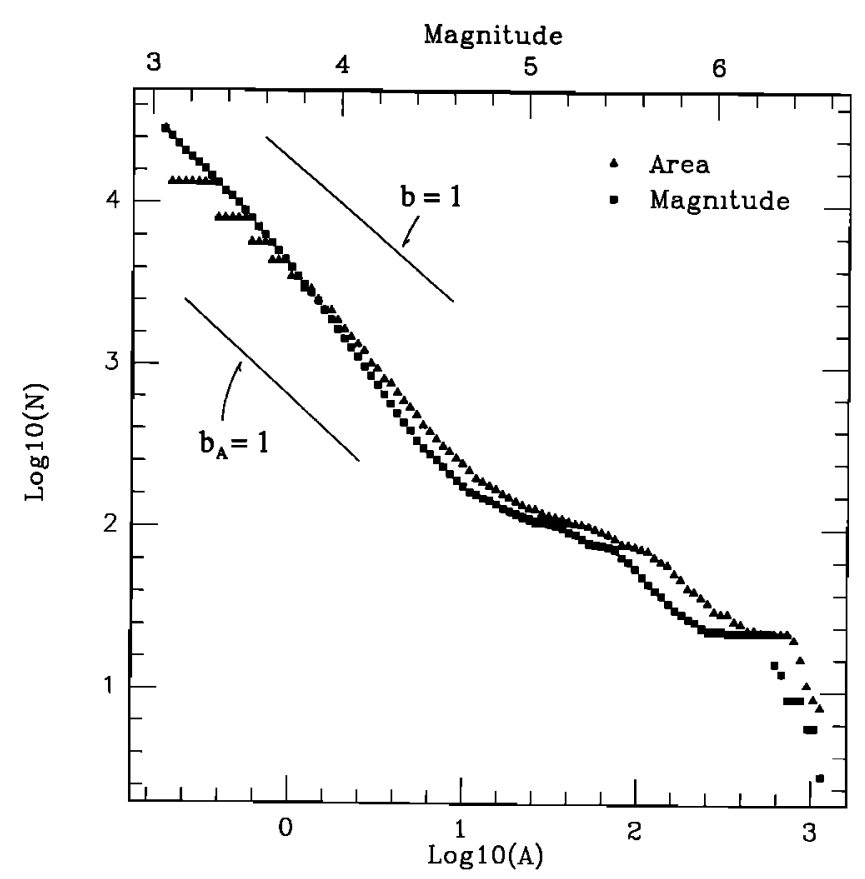

Fig. 14. Cumulative FS statistics for event magnitude (squares) and rupture area (triangles) for a grid having $160 \times 40$ cells and the stress drop distribution of Figure $11 a$. The results are similar to those obtained with $128 \times 32$ cells (Figure 13a). 
by Rundle [1989], assuming that events of all size cover the same fault area (similar geometrical argument was used earlier by Kanamori and Anderson [1975] to derive $b \approx 1$ for small earthquakes) and that small and large events propagate in two dimensions and one dimension respectively. The assumption of constant fault area for events of all size, while being reasonable for a collection of faults having a fractal areal distribution, may not be applicable to individual faults or to regions with approximately uniform faults. Indeed, observations focusing on specific faults (Figure 15, Schwartz and Coppersmith, [1984], Wesnousky, submitted manuscript, 1993) or uniform seismogenic zones [Main and Burton, 1984; Main, 1987; Main and Burton, 1989; Trifu and Radulian, 1991] show significant deviations from log-log linear GR relations.

Our simulated FS statistics, corresponding to a single fault, contain three regions: an initial self-similar (power law) GR domain with $b \approx 1.2, b_{\mathrm{A}} \approx 1$, an intermediate region with enhanced seismicity and a local maximum in the frequency of events having rupture area with the dimension of the upper layer thickness, and a final steep decay ending with a pronounced peak for events having a size of the order of the whole system (see, e.g., Figure $10 a$ ). A power law region (usually with $b$ or $b_{\mathrm{A}} \approx 1$ ) is simulated by all models that generate, one way or another, a critical state (e.g., the spring-block and cellular automata models mentioned in the introduction). Thus the ability of a model to simulate a $b, b_{\mathrm{A}} \approx 1$ region is not a strong indication that the model corresponds to a system of earthquake faults. Rather, models should be appraised on the basis of their success in simulating details outside the $b, b_{\mathrm{A}} \approx 1$ domain, relevant to earthquake rupture. We note that characteristics of individual faults or uniform seismogenic zones in observed data are shown not in the $b$ $\approx 1$ region but in deviations from self-similarity [e.g., Main, 1987; Wesnousky, submitted manuscript, 1993]. Such characteristics may be lost in FM statistics of data that are taken from irregular seismogenic zones such as southern California [Hileman et al., 1973] or the whole Earth [Pacheco et al., 1992].

Figure 15 shows the observed number of earthquakes per 100 years versus magnitude for the SAF at Parkfield, California. The microearthquake distribution defines a selfsimilar line with $b \approx 0.9$ [Malin et al., 1989]. The frequency of occurrence of five $M=6$ Parkfield earthquakes in a century is, however, strongly enhanced with respect to self-similarity, in agreement with our model simulations. Our model frequency-size statistics are qualitatively similar also to the fault specific FM data of Schwartz and Coppersmith [1984] for the Wasatch fault in Utah, and Wesnousky (submitted manuscript, 1993) for the WhittierElsinore, Garlock, and San Andreas faults, and segments of the San Jacinto fault zone in southern California. Local maxima in the rate of occurrence of intermediate and large size events, similar to what is simulated in our model, are present also in the regional FM data of Main and Burton [1984] for earthquakes in the New Madrid seismic zone, Main [1987] for seismicity in Mount Saint Helens, Main and Burton [1989] for the Aegean area, and Trifu and Radulian [1991] for the Vrancea seismic zone in Romania. Kagan [1993] emphasizes that the definition of a specific fault is problematic due to the complexity of the crust and the possible circular use of the limited available data. These difficulties, however, should not apply to the regional seismicity data cited above.

Trifu and Radulian [1991] explained deviations in their data from self-similarity in terms of a variant to the percolation model of Lomnitz-Adler [1985]. The blockspring calculations of Carlson and Langer [1989] and the hierarchical model of Narkounskaia and Shnirman [1990] also produce nonlinear $(\log -\log )$ FS statistics. Our study indicates that local maxima in FS statistics of earthquakes in a 3-D elastic medium correspond to dimensions of coherent brittle zones, such as the width of the seismogenic layer (the upper crust in our model) or the length of a fault segment bounded by strong or weak barriers (the computational grid in our model). The FM statistics of seismicity observed along specific fault zones show, in most cases, a similar increase in the frequency of events having "characteristic" rupture dimensions (but see Kagan [1993]). Exceptions to this rule may be found in the FM data of Wesnousky (submitted manuscript, 1993) for the Newport-Inglewood fault and the combined San Jacinto fault zone in southern California. Seismotectonic studies

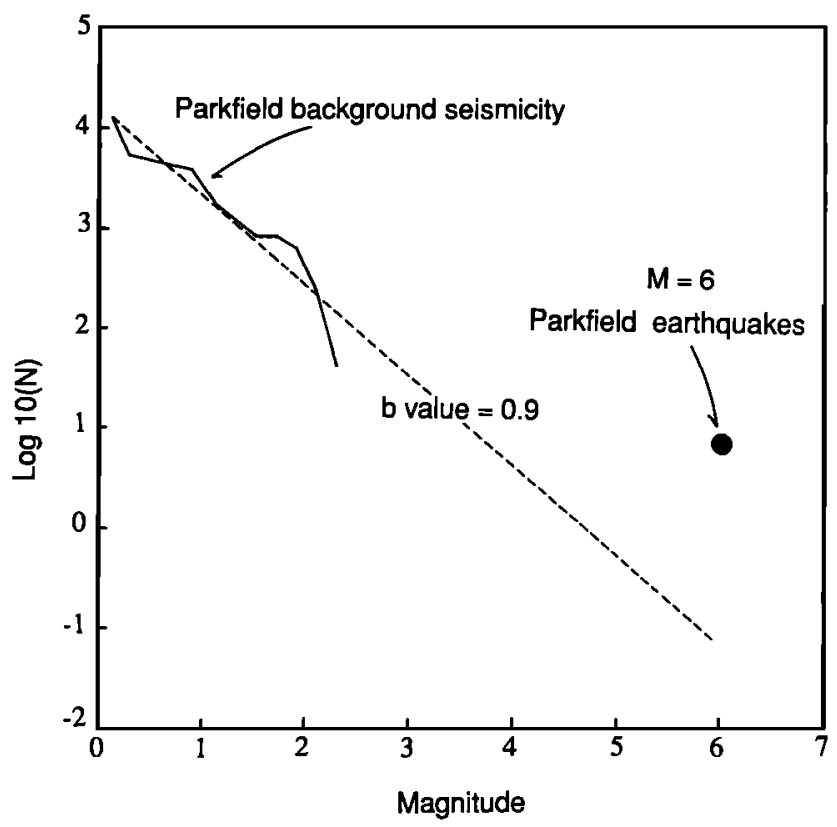

Fig. 15. Noncumulative frequency-magnitude statistics of observed Parkfield data. The microearthquake distribution is from Malin et al. [1989]. The five $M=6$ Parkfield earthquakes per 100 years fall above the straight, $b=0.9$, self-similar line defined by small events, in agreement with our model calculations. 
by Sanders and Kanamori [1984] and others show, however, that the depth of the seismogenic layer and the length, strike, and dip of fault segments in the San Jacinto fault zone are all highly variable. Similarly, the fault-tracecomplexity analysis of Wesnousky (submitted manuscript, 1993) indicates that the Newport-Inglewood fault consists of many disjoint segments. In these circumstances, as in the cases of the complex southern California region or the entire Earth, local maxima associated with rupture dimensions corresponding to the width of the seismogenic zone and characteristic asperity/barrier spacing will be averaged out. On the other hand, in places where the seismogenic layer is more or less uniform, local maxima may be preserved in FM statistics of regional data. This holds, for instance, in the case of the seismicity preceding the eruption of Mount Saint Helens, where the FM statistics show a clear local maximum in the rate of occurrence of events having a source dimension equal to the width of the seismogenic zone above the magma chamber [Main, 1987]. Another example is the peak in the rate of occurrence of earthquakes in the Aegean area with rupture dimension of $10-14 \mathrm{~km}$ [Main and Burton, 1989]. Independent seismotectonic studies in the Aegean area [e.g., Ekstrom and England, 1989] indicate that the brittle crust in that region has indeed an approximately uniform thickness of about $10 \mathrm{~km}$ and that most earthquakes there occur on steeply dipping faults with rupture areas bounded by the width of the seismogenic layer.

The supercritical rupture growth in our model is a direct manifestation of the 3-D elastic stress transfer calculations used in the simulations. This can be illustrated by a simple analysis of fracture mechanics type based on elastic stress concentration. Consider a full space having a circular crack with a radius $R$ over which a uniform stress drop $\Delta \tau$ is applied and stress $\tau_{\mathrm{a}}$ remains on the ruptured surface. The stress at a small distance $r$ from the crack front is given asymptotically as

$$
\tau=K /(2 \pi r)^{1 / 2}+\tau_{\mathrm{a}}
$$

where $K=\gamma \Delta \tau(4 R / \pi)^{1 / 2}$ is the stress intensity factor and, assuming a Poisson ratio of $0.25, \gamma=1.14$ and 0.86 for positions along the crack front where the shearing conditions are pure mode II (inplane) and III (antiplane), respectively [Dmowska and Rice, 1986, equation 3.2.14]. Denoting the size of a discrete computational cell by $h$ and calculating stress at the cell center by setting $r=h / 2$ we get

$$
\tau=(2 / \pi) \gamma \Delta \tau(R / h)^{1 / 2}+\tau_{\mathrm{a}}
$$

Putting into (5), $\Delta \tau=p\left(\tau_{\mathrm{s}}-\tau_{\mathrm{a}}\right)$, with $p$ being an effective coefficient of weighted average stress drop in the rupture area, the ratio $R / h$ for which the left hand side of (5) is just equal to the (static) failure stress $\tau_{\mathrm{s}}$ is

$$
R / h \sim(\pi / 2 p)^{2} \text {. }
$$

This may be interpreted as the size of a rupture for which the stress concentrated around its perimeter is large enough to cause failure of all the border cells, i.e., an unstoppable rupture. We may expect that the average prestress over a large multicell region, within which failures of small subregions are occurring more or less randomly, will be approximately midway between $\tau_{\mathrm{s}}$ and $\tau_{\mathrm{a}}$. This argues for $p \approx 0.5$, or slightly larger since the actual stress at the end of a failure episode is distributed between $\tau_{a}$ and $\tau_{d}$.

Unfortunately, it is not easy to substantiate relation (6) by running many models with different cell size. This is because data generated by models using large cells are noisy, while data generated by models having small cells require large computation time. Table 1 shows critical crack size versus the size of the used cell for four runs (assuming the stress drop distribution of Figure $11 a$ ) having $80 \times 20$, $100 \times 25,128 \times 32$, and $160 \times 40$ cells. The critical crack size is determined by equating the rupture area at the end of the self-similar region (Figures $16 a-16 d$ ) to the area of a circular crack. The ratio $R / h$ is nearly a constant (with some scatter attributed to inaccuracies in simulations with large cells) as predicted by equation (6). As the cell size is reduced, the results define a critical area at the end of the scaling range more accurately (e.g., compare Figure $16 d$ to Figures $16 a-16 c$ ). From the entries of Table 1 the effective coefficient of the average stress drop in the ruptured area is evaluated as $p \approx 0.55$. This value is close to 0.50 as estimated above.

We note that the supercritical crack growth simulated here is not accounted for by cellular automata and blockspring models in which the adopted simplified stress transfer laws fail to scale properly with increasing rupture size. The power law scaling range in our simulations is terminated by events having rupture area of about 200 times the cell size $\left(A \approx \pi(8.3 h)^{2}\right.$ based on $R / h$ of Table 1$)$. Thus our FS statistics for a cellular fault show GR power law distribution of events spanning only 2 earthquake

TABLE 1. Parameters for Supercritical Crack Growth

\begin{tabular}{cccccc}
\hline Number of Elements & $A=\pi R^{2}, \mathrm{~km}^{2}$ & $R, \mathrm{~km}$ & $h, \mathrm{~km}$ & $R / h$ & $A / h^{2}$ \\
\hline $80 \times 20$ & 158 & 7.09 & 0.875 & 8.1 & 206 \\
$100 \times 25$ & 112 & 5.97 & 0.7 & 8.5 & 227 \\
$128 \times 32$ & 63 & 4.48 & 0.546 & 8.2 & 211 \\
$160 \times 40$ & 40 & 3.56 & 0.437 & 8.1 & 206 \\
\hline
\end{tabular}

$A$ is the rupture area at the end of the self-similar regions in Figures $16 a-16 d, R=(A / \pi)^{1 / 2}$ is the radius of a critical circular crack, and $h$ is the size of the used cell. 
magnitudes. This is in contrast to the earthquake statistics of Wesnousky (submitted manuscript, 1993) and Main and Burton [1984] for the San Andreas fault in southern California and the New Madrid seismic zone, where GR power law distributions are shown to cover 3 earthquake magnitudes or more. We note, however, that the FM statistics of Wesnousky (submitted manuscript, 1993) for the Whittier-Elsinore and Garlock faults, and segments of the San Jacinto fault zone, as well as the data presented by

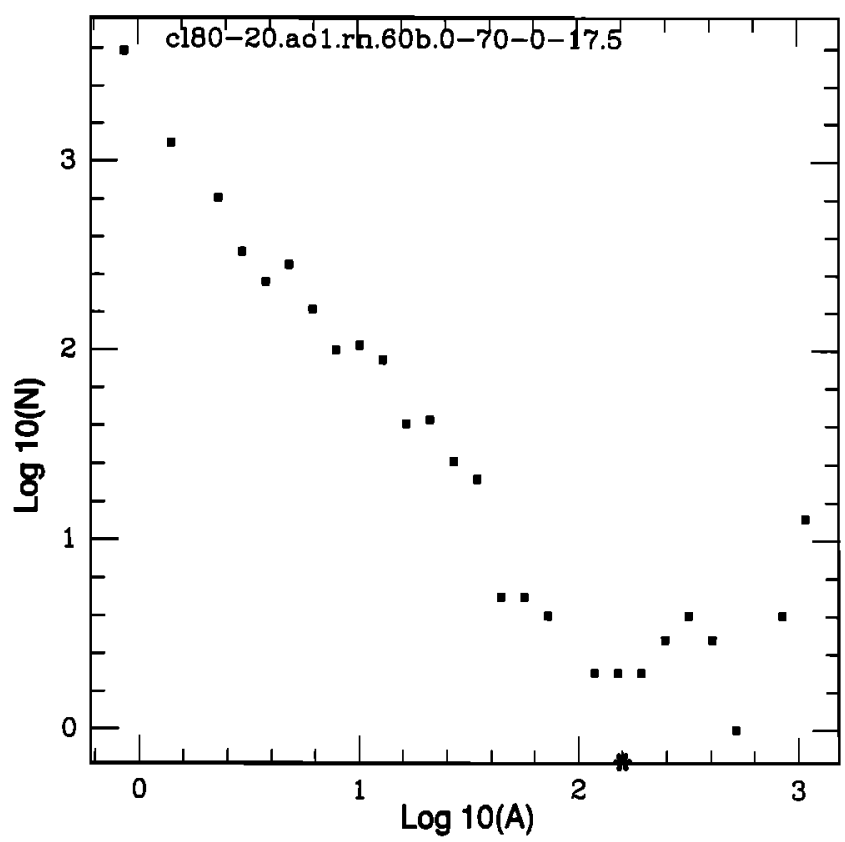

Fig. 16a. Noncumulative FS statistics for rupture area using 80 x 20 cells. Critical event size is marked by an asterisk. The assumed stress drop distribution is shown in Figure $11 a$.

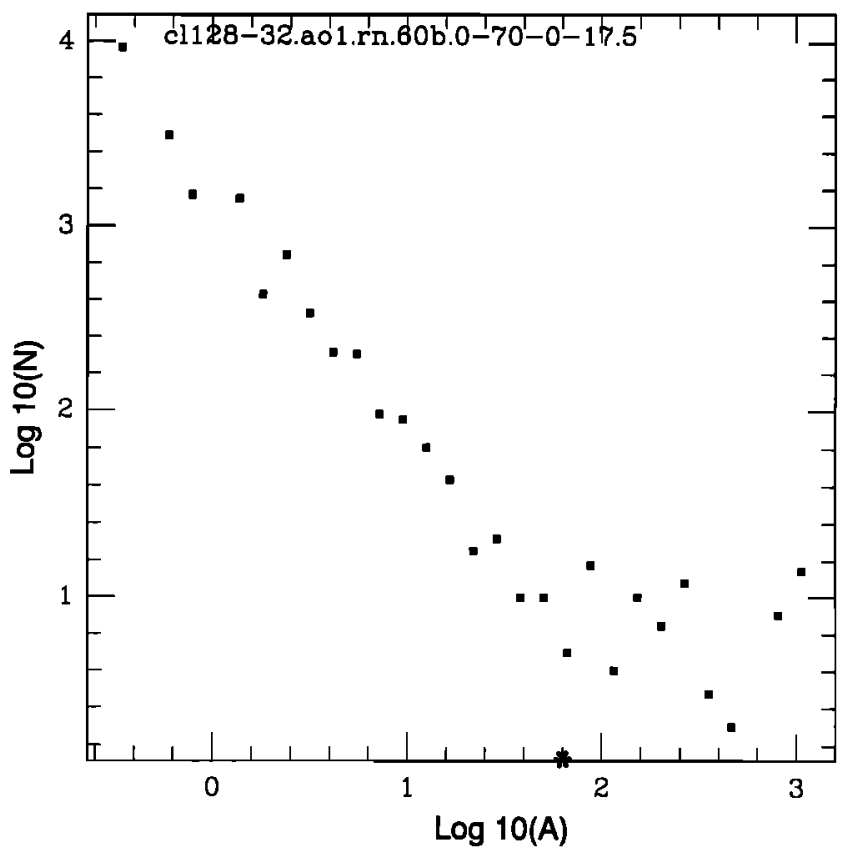

Fig. 16c. Same as Figure $16 a$ for $128 \times 32$ cells.
Schwartz and Coppersmith [1984], Main [1987], Main and Burton [1989], and Trifu and Radulian [1991], all show power law distributions that cover only about 2 orders of earthquake magnitude. The range of self-similarity in actual earthquake statistics can, of course, extend toward the lowmagnitude range, where the data may be incomplete. We recall, however, that Sacks and Rydelek [1992] and other studies mentioned in the introduction argue that small earthquakes do not follow a self-similar GR distribution due

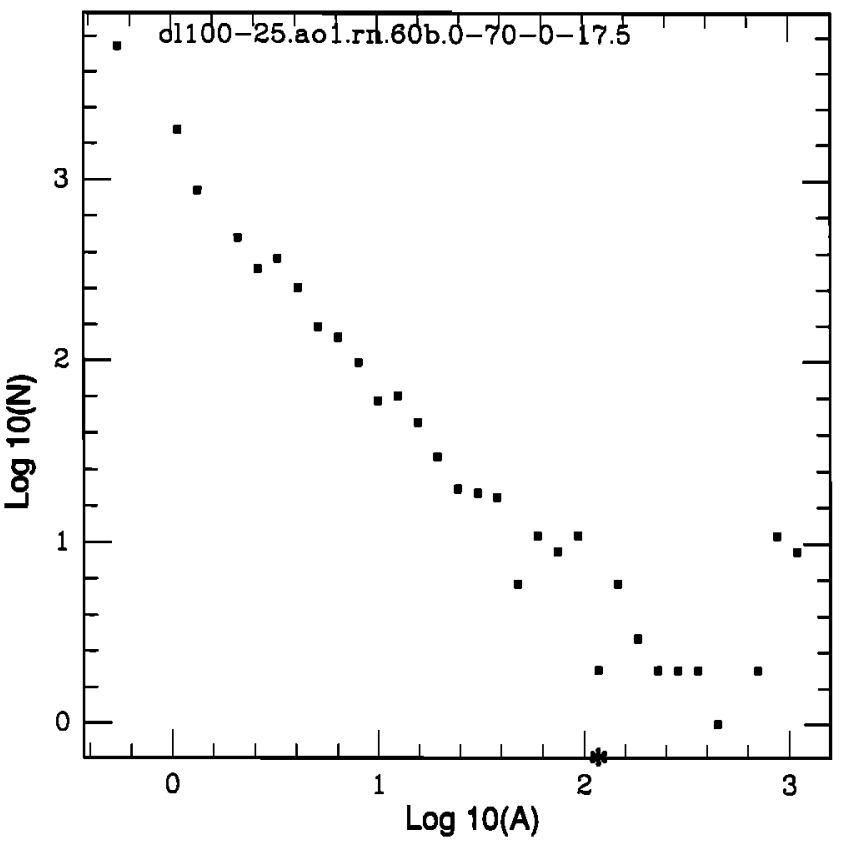

Fig. 16b. Same as Figure $16 a$ for $100 \times 25$ cells.

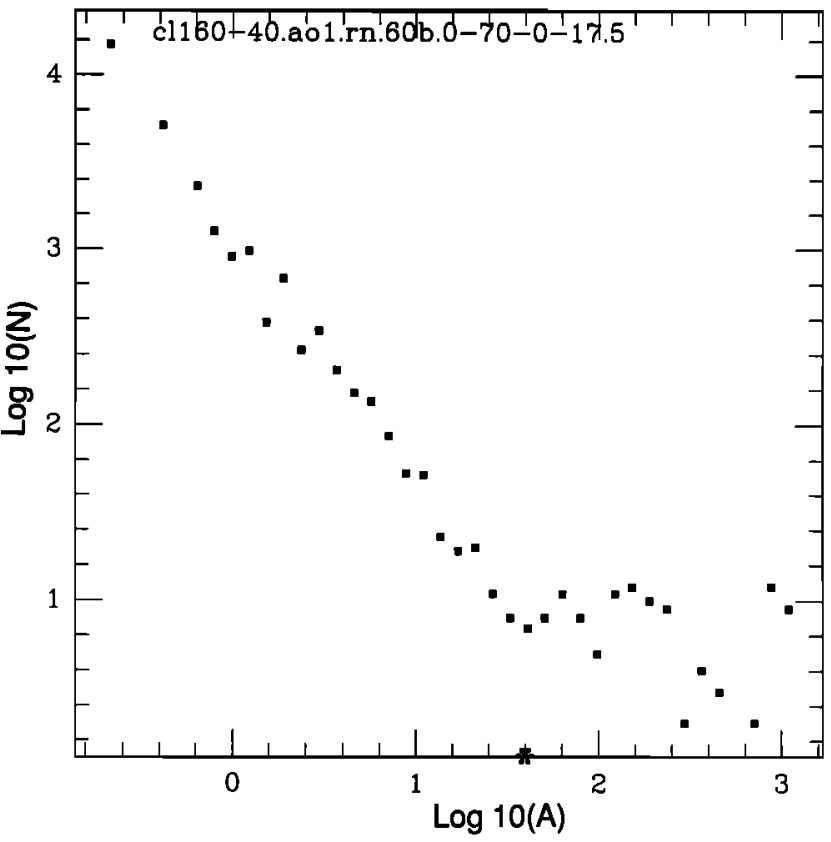

Fig. 16d. Same as Figure $16 a$ for $160 \times 40$ cells. 
to the discreteness of fault zone structure and failure of small slip patches by creep. Since the scaling region in our simulations is proportional to $h^{2}$ (Table 1), our results indicate that the area range of events following power law FS distribution, in a fault having a single cell size $h$, vanishes as $h$ is reduced to zero. A tentative conclusion is that a broad GR power law scaling region of observed earthquakes is the result of geometric fault zone disorder spanning a broad range of size scales. The simple cellular automata and block-spring models miss the fact that a single cell size can produce GR power law statistics only over a limited range since they do not include proper scaling of stress concentration with event size.

Our simulated results can be used to examine scaling relations between potency release $P$ and rupture area $A$. Figures $17 a$ and $17 b$ show $\log (P)$ versus $\log (A)$ for the stress drop distribution cases 1 and 4 of the previous section (significant average property variation plus small random fluctuations along the fault, and uniform stress drop distribution, respectively). The results show $\log (P) \approx(3 / 2)$ $\log (A)+$ const for events having about $P \geq 10^{2}$ square kilometers times centimeters $(M \geq 4.9)$ in agreement with the analysis of $A k i$ [1972] and Kanamori and Anderson [1975]. For events with about $P \leq 10^{2}$ square kilometers times centimeters the results, however, are better described by $\log (P) \approx \log (A)+$ const. We note that our small events are not covered by the data of $A k i$ [1972] and Kanamori and Anderson [1975]. The recent data compilation of Romanowicz [1992] shows that the scaling relation $\log (P)$ $\approx(3 / 2) \log (A)+$ const breaks down also for large strike-slip earthquakes. While the break in the scaling $\log (P) \approx(3 / 2)$ $\log (A)+$ const for large strike-slip earthquakes (related to the change from $b \approx 1$ for small events to $b \approx 1.5$ for large ones [Rundle, 1989; Pacheco et al., 1992]) is readily understood as a consequence of a predominantly 1-D rupture propagation for long and narrow faults, we cannot offer an explanation for the scaling $\log (P) \approx \log (A)+$ const of our simulated small events.

Our model calculations may be considered as providing a few simple representations of the SAF in central California. The simulated results show an irregular sequence of Parkfield-type earthquakes and a great diversity in the failure mechanism of the model asperity. We thus suggest that it is unrealistic to expect a complex crustal system like the SAF to produce periodic earthquakes and/or simple precursory patterns repeating from one event to the other. It is possible, however, that precursory patterns do exist in the form of complex, perhaps evolving, combinations of parameters. A useful strategy for earthquake prediction might employ large synthetic data sets, generated over many earthquake cycles and various model realizations, to "train" pattern recognition algorithms. These algorithms may then be applied to real earthquake data [e.g, Keilis-Borok, 1990].

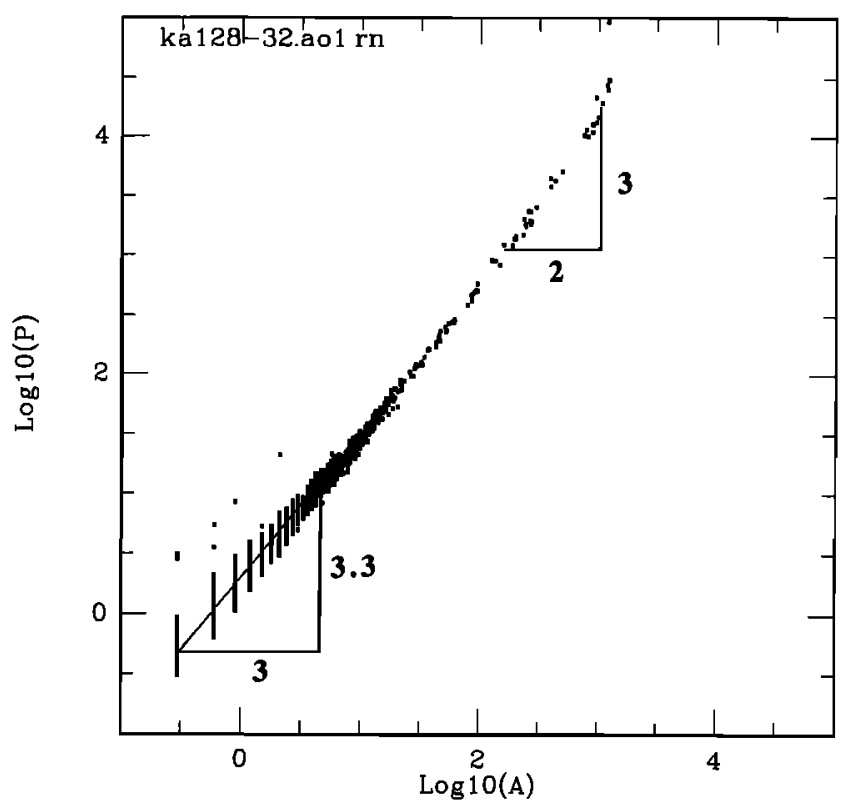

Fig. 17a. Log (potency) versus $\log$ (area) for the stress drop distribution of Figure $11 a$. Events having about $P \leq 10^{2} \mathrm{~km}^{2}$ $\mathrm{cm}(M \leq 4.9)$ are characterized by $\log (P) \approx 1.1 \log (A)+$ const, while events with about $P \geq 10^{2} \mathrm{~km}^{2} \mathrm{~cm}$ follow the scaling $\log (P) \approx(3 / 2) \log (A)+$ const.

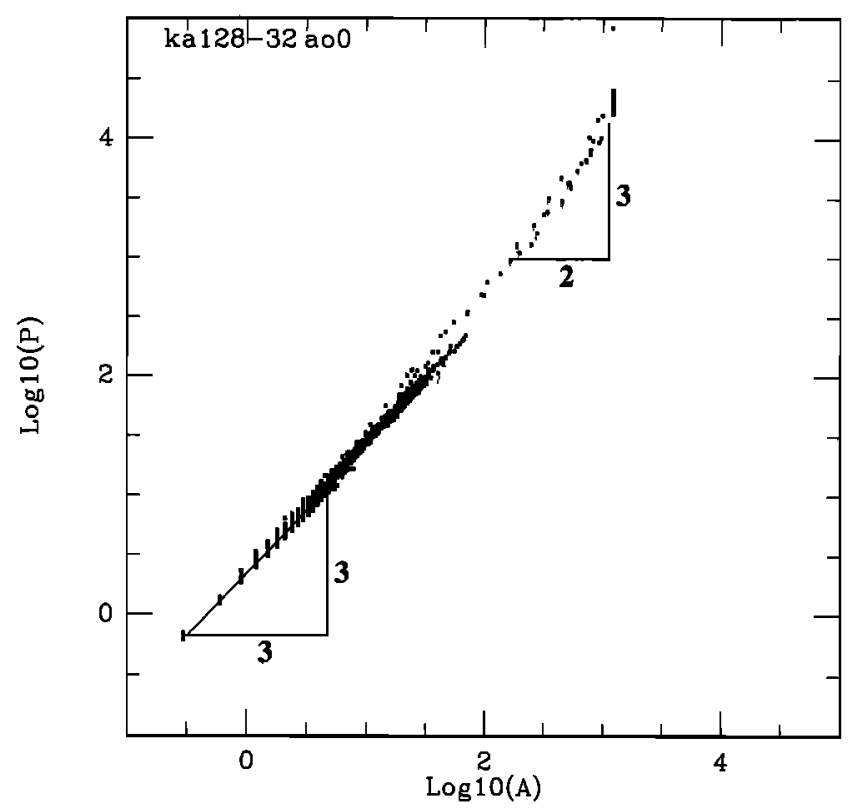

Fig. 17b. Same as Figure $17 a$ for homogeneous stress drop distribution along the fault. Here the scaling of small events $(P$ $\left.\leq 10^{2} \mathrm{~km}^{2} \mathrm{~cm}, M \leq 4.9\right)$ is $\log (P) \approx \log (A)+$ const.

Acknowledgments. We thank Alexander Gusev, Peter Leary, Galina Narkounskaia, John Rundle, and Terry Tullis for discussions, Rick O'Connell for access to a cluster of Sun computers, and Steve Wesnousky for a preprint of his work. Figure 15 was provided by Peter Leary. The manuscript benefited from comments by Yan Kagan, Ian Main, Bill Stuart, and anonymous journal reviewer and associate editor. The work was supported by the Southern California Earthquake Center (subcontract 569928 from USC, based on NSF support) and, in earlier phases, by NSF grant EAR 90-04556. 


\section{REFERENCES}

Abercrombie, R., and P. Leary, Source parameters of small earthquakes recorded at $2.4 \mathrm{~km}$ depth, Cajon Pass, southern California: implications for earthquake scaling, Geophys. Res. Lett., in press, 1993.

Aki, K., Earthquake mechanism, Tectonophysics, 13, 423 446, 1972.

Aki, K., Asperities, barriers, characteristic earthquakes, and strong motion prediction, J. Geophys. Res., 89, 5867-5872, 1984.

Aki, K., Magnitude-frequency relation for small earthquakes: A clue to the origin of $f_{\text {max }}$ of large earthquakes, $J$. Geophys. Res., 92, 1349-1355, 1987.

Allen, C. R., The tectonic environments of seismically active and inactive areas along the San Andreas fault system, in Proceedings of the Conference on Geological Problems of the San Andreas Fault System, Stanford Univ. Publ. Geol. Sci., 11, 70-82, 1968.

Anderson, J., Implication of attenuation for studies for the earthquake source, in Earthquake Source Mechanics, Geophys. Monogr. Ser., vol. 37, edited by S. Das, J. Boatwright, and C. H. Scholz, pp. 311-318, AGU, Washington, D. C., 1986.

Antolik, M., W. Foxall, A. Michelini, and T. E. McEvilly, Microearthquake clusters at Parkfield: Constraint on faultzone structure and failure processes, Eos Trans. $A G U, 72(44)$, Fall Meeting suppl., 483, 1991.

Aviles, C. A., C. H. Scholz, and J. Boatwright, Fractal analysis applied to characteristic segments of the San Andreas fault, $J$. Geophys. Res., 92, 331-334, 1987.

Bak, P., and C. Tang, Earthquakes as self-organized critical phenomena, J. Geophys. Res., 94, 15,635-15,637, 1989.

Bakun, W. H., and A. G. Lindh, The Parkfield, California, prediction experiment, Earthquake Predict. Res., 3, 285-304, 1985.

Bakun, W. H., and T. V. McEvilly, Recurrence models and Parkfield, California, earthquakes, J. Geophys. Res., 89, 3051-3058, 1984.

Bakun, W. H., C. G. Bufe, and R. M. Stewart, Body wave spectra of central California earthquakes, Bull. Seismol. Soc. Am., 66, 439-459, 1976.

Ben-Zion, Y., The response of two joined quarter spaces to $\mathrm{SH}$ line sources located at the material discontinuity interface, Geophy. J. Int., 98, 213-222, 1989.

Ben-Zion, Y., Structure of a few fault segments in California from travel time inversion and waveform modeling of fault zone seismic waves, Ann. Geophys., 11, suppl. I, c47, 1993.

Ben-Zion, Y., J. R. Rice, and R. Dmowska, Interaction of the San Andreas fault creeping segment with adjacent great rupture zones, and earthquake recurrence at Parkfield, $J$. Geophys. Res., 98, 2135-2144, 1993.

Brown, S., J. B. Rundle, and C. H. Scholz, A simplified springblock model of earthquakes, Geophys. Res. Lett., 18, 215218, 1991.

Burford, R. O., and P. W. Harsh, Slip on the San Andreas fault in central California from alignment array surveys, Bull. Seismol. Soc. Am., 70, 1233-1261, 1980.

Burridge, R., and L. Knopoff, Model and theoretical seismicity, Bull. Seismol. Soc. Am., 57, 341-371, 1967.

Byerlee, J. D., Friction of rocks, Pure Appl. Geophys., 116, 615-626, 1978.

Carlson, J. M., A two dimensional model of a fault, Phys. Rev. A, 44, 6226-6232, 1991.
Carlson, J. M. and J. S. Langer, Mechanical model of an earthquake, Phys. Rev. A, 40, 6470-6484, 1989.

Carlson, J. M., J. S. Langer, B. Shaw, and C. Tang, Intrinsic properties of a Burridge-Knopoff model of a fault, Phys. Rev. $A, 44,884-897,1991$.

Chinnery, M., The stress changes that accompany strike-slip faulting, Bull. Seismol. Soc. Am., 53, 921-932, 1963.

Chouet, B., K. Aki, and M. Tsujiura, Regional variation of the scaling law of earthquake source spectra, Bull. Seismol. Soc. Am., 68, 49-79, 1978.

Christensen, K. and Z. Olami, Variation of the GutenbergRichter b values and nontrivial temporal correlations in a spring-block model for earthquakes, J. Geophys. Res., 97, 8729-8735, 1992.

Dieterich, J. H., A model for the nucleation of earthquake slip, in Earthquake Source Mechanics, Geophys. Monogr. Ser., vol. 37, edited by S. Das, J. Boatwright, and C. H. Scholz, pp. 37-47, AGU, Washington, D. C., 1986.

Dmowska, R., and J. R. Rice, Fracture theory and its seismological applications, in Continuum Theories in Solid Earth Physics, edited by R. Teisseyre, pp. 187-255, PWN Polish Scientific Publishers, Warsaw, 1986.

Ekstrom, G., and P. England, Seismic strain in regions of distributed continental deformation, J. Geophys. Res., 94, 10, 231-10, 257, 1989.

Fletcher, J. B., Spectra from high-dynamic range digital recording of Oroville, California, aftershocks and their source parameters, Bull. Seismol. Soc. Am., 70, 735-755, 1980.

Gusev, A. A., Multiasperity fault model and the nature of shortperiod subsources, Pure. Appl. Geophys., 130, 635-660, 1989.

Hanks, T. C., Small earthquakes, tectonic forces, Science, 256, 1430-1432, 1992.

Hanks, T. C., and H. Kanamori, A moment magnitude scale, $J$. Geophys. Res., 84, 2348-2350, 1979.

Harris, R. A., and P. Segall, Detection of a locked zone at depth on the Parkfield, California, segment of the San Andreas fault, J. Geophys. Res., 92, 7945-7962, 1987.

Heaton, T. H., Evidence for and implications of self-healing pulses of slip in earthquake rupture, Phys. Earth Planet. Inter., 64, 1-20, 1990.

Heaton, H. T. , and R. E. Heaton, Static deformation from point forces and force couples located in welded elastic Poissonian half-spaces: implications for seismic moment tensors, Bull. Seismol. Soc. Am., 79, 813-841, 1989.

Hileman, J. A., C. R. Allen and J. M. Nordquist, Seismicity of the southern California region 1st Jan. 1932 to 31 st Dec. 1972, Contrib. 2385, Div. of Geol. and Planet. Sci., Calif. Inst. of Technol., Pasadena, 1973.

Horowitz, F. G., and A. Ruina, Slip patterns in a spatially homogeneous fault model, J. Geophys. Res., 94, 10,279$10,298,1989$.

Hough, S. E., H. Gue, A. Lerner-Lam, S. Seeber, and C. Scholz, Stress drop scaling: results from empirical Green's function study of Loma Prieta aftershocks, Seismol. Res. Lett., 63(1), $24,1992$.

Ito, K., and M. Matsuzaki, Earthquakes as self organized critical phenomena, J. Geophys. Res., 95, 6853-6860, 1990.

Kagan, Y. Y., Fractal dimension of brittle fracture, J. Nonlinear Sci., 1, 1-16, 1991.

Kagan, Y. Y., Statistics of characteristic earthquakes, Bull. Seismol. Soc. Am., 83, 7-24, 1993. 
Kanamori, H., and D. L. Anderson, Theoretical basis of some empirical relations in seismology, Bull. Seismol. Soc. Am., 65, 1073-1095, 1975.

Keilis-Borok, V. I., The lithosphere of the earth as a nonlinear system with implications for earthquake prediction, Rev. Geophys., 28, 19-34, 1990.

Leary P., Deep borehole log evidence for fractal distribution of fractures in crystalline rock, Geophys. J. Int., 107, 615-627, 1991.

Leary, P. and Y. Ben-Zion, A $200 \mathrm{~m}$ wide fault zone low velocity layer on the San Andreas fault at Parkfield: Results from analytic waveform fits to trapped wave groups, Seismol. Res. Lett., 63(1), 62, 1992.

Li, V. C., and J. R. Rice, Crustal deformation in great California earthquake cycles, J. Geophys. Res., 92, 11,533$11,551,1987$.

Lisowski, M., and W. H. Prescott, Short-range distance measurements along the San Andreas fault system in central California, 1975-1979, Bull. Seismol. Soc. Am., 71, 1607$1624,1981$.

Lomnitz-Adler, J., Asperity models and characteristic earthquakes, Geophys. J. R. Astron. Soc., 83, 435-450, 1985.

Madariaga, R., Dynamics of an expanding circular fault, Bull. Seismol. Soc. Am., 66, 639-666, 1976.

Main, I. G., A characteristic earthquake model of the seismicity preceding the eruption of Mount St. Helens on 18 May 1980, Phys. Earth Planet. Inter., 49, 283-293, 1987.

Main, I. G., and P. W. Burton, Physical links between crustal deformation, seismic moment and seismic hazard for regions of varying seismicity, Geophys. J. R. Astron. Soc., 79, 469488, 1984.

Main, I. G. and P. W. Burton, Seismotectonics and the earthquake frequency-magnitude distribution in the Aegean area, Geophys. J., 98, 575-586, 1989.

Malin, P. E., S. N. Blakeslee, M. G. Alvarez, and A. J. Martin, Microearthquake imaging of the Parkfield asperity, Science, 244, 557-559, 1989.

Narkounskaia, G., and M. G. Shnirman, Hierarchical model of defect development and seismicity, Phys. Earth Planet. Inter., 61, 29-35, 1990.

Narkounskaia, G., J. Huang, and D. L. Turcotte, Chaotic and self-organized critical behavior of a generalized slider-block model, J. Statist. Phys., 67, 1151-1183, 1992.

Okada, H., H. Watanabe, H. Yamashita, and I. Yokoyama, Seismological significance of the 1977-1978 eruptions and magma intrusion process of Usu Volcano, Hokkaido, $J$. Volcanol. Geotherm. Res., 9, 311-344, 1981.

Okubo, P., and K. Aki, Fractal geometry in the San Andreas fault system, J. Geophys. Res., 92, 345-355, 1987.

O'Neill, M. E., Source dimensions and stress drops of small earthquakes near Parkfield, California, Bull. Seismol. Soc. Am., 74, 27-40, 1984.

Pacheco, J. F., C. H. Scholz, and L. R. Sykes, Changes in frequency-size relationship from small to large earthquakes, Nature, 255, 71-73, 1992.

Papageorgiou, A., and K. Aki, A specific barrier model for the quantitative description of inhomogeneous faulting and the prediction of strong ground motion, I, Description of the model, Bull. Seismol. Soc. Am., 73, 693-722, 1983.

Power, W. L., and T. E. Tullis, Euclidian and fractal models for the description of rock surface roughness, J. Geophys. Res., 96, 415-424, 1991.

Power, W. L., T. E. Tullis, and J. D. Weeks, Roughness and wear during brittle faulting, J. Geophys. Res., 93, 15,268$15,287,1988$.

Rice, J. R., Variable earthquake recurrence intervals at Parkfield, Eos Trans. $A G U, 73(43)$, Fall Meeting suppl., 407, 1992.

Rice, J. R., Spatio-temporal complexity of slip on a fault, $J$. Geophys. Res., 98, 9885-9907, 1993.

Romanowicz, B., Strike-slip earthquakes on quasi-vertical transcurrent faults: inferences for general scaling relations, Geophys. Res. Lett., 19, 481-484, 1992.

Rundle, J. B., A physical model for earthquakes, 1, Fluctuations and interactions, J. Geophys. Res., 93, 62376254, 1988.

Rundle, J. B., Derivation of the complete Gutenberg-Richter magnitude-frequency relation using the principle of scale invariance, J. Geophys. Res., 94, 12,337-12,342, 1989.

Rydelek, P. A., and I. S. Sacks, Testing the completeness of earthquake catalogues and the hypothesis of self-similarity, Nature, 337, 251-253, 1989.

Sacks, S. E. and P. A. Rydelek, Quantum earthquake concept, Seismol. Res. Lett., 63(1), 75, 1992.

Sanders, C. O., and H. Kanamori, A seismotectonic analysis of the Anza seismic gap, San Jacinto fault zone, southern California, J. Geophys. Res., 89, 5873-5890, 1984.

Savage, J. C., and W. H. Prescott, Asthenosphere readjustment and the earthquake cycle, J. Geophys. Res., 83, 3369-3376, 1978.

Schultz, S. S., G. M. Mavko, R. O. Burford, and W. D. Stuart, Long-term fault creep observations in central California, $J$. Geophys. Res., 87, 6977-6982, 1982.

Schwartz, D. P. and K. J. Coppersmith, Fault behavior and characteristic earthquakes: Examples from the Wasatch and San Andreas fault zones, J. Geophys. Res., 89, 5681-5698, 1984.

Sibson, R. H., Fault zone models, heat flow, and the depth distribution of earthquakes in the continental crust of the United States, Bull. Seismol. Soc. Am., 72, 151-163, 1982.

Trifu, C.-I., and M. Radulian, Frequency-magnitude distribution of earthquakes in Vrancea: Relevance for a discrete model, $J$. Geophys. Res., 96, 4301-4311, 1991.

Tse, S. T., and J. R. Rice, Crustal earthquake instability in relation to the depth variation of frictional slip properties, $J$. Geophys. Res., 91, 9452-9472, 1986.

Y. Ben-Zion and J. R. Rice, Department of Earth and Planetary Sciences, Harvard University, 20 Oxford Street, Cambridge, MA 02138.

(Received October 30, 1992; revised April 5, 1993; accepted April 23, 1993.) 